\title{
LA PRODUCTIVIDAD TOTAL DE LOS FACTORES EN LA AGRICULTURA ESPAÑOLA: EL CASO DEL SUR DE NAVARRA, 1780-1900*
}

\author{
JOSÉ-MIGUEL LANA-BERASAIN \\ Universidad Pública de Navarra / Nafarroako Unibertsitate Publikoa ${ }^{\text {a }}$
}

\begin{abstract}
The aim of this article is to measure the advance of agricultural productivity in South Navarra between 1780 and 1900. The construction of several indices of agricultural commodities and factor prices allows us to apply the methodology of Total Factor Productivity (TFP). As distinguished from the thesis of stagnation, our estimate of the annual rate of TFP growth in the long run is close to $0.42 \%$. This rate was particularly high between 1817 and 1850 , in a context of deflation and institutional change. During the second half of the century the cyclical evolution of the curve reveals the obstacles derived from the capital resources supply, especially fertilizers and animal traction.
\end{abstract}

Keywords: Total Factor Productivity, Agricultural Factor Cost, Agricultural Prices

JEL codes: Q11, Q12, R32, N53, N93

* Received 4 January 2011. Accepted 10 June 2011. Este artículo forma parte del proyecto HAR2009-09700, financiado por la Dirección General de Investigación y Gestión del Plan Nacional de $\mathrm{I}+\mathrm{D}+\mathrm{i}$. Versiones previas fueron discutidas en seminarios de la UPNA-NUP, UCM, UAMIztapalapa, Lund University, I. Gerónimo de Uztariz y AEHE. El autor agradece las críticas de los participantes en esos eventos, y en particular las de los profesores E.Llopis, C.O'Grada, D.Gallego, R.Garrabou, J.I.Jiménez-Blanco, A.Tortolero, J.Nieto, E.Sánchez Iriso, J.de la Torre, y cuatro evaluadores anónimos. El autor está en deuda además con los responsables de los archivos consultados en Tudela, Toledo y Pamplona, y las familias depositarias de los fondos documentales de San Adrián y Zaldívar.

a Dpto. Economía / Ekonomia Saila, Universidad Pública de Navarra / Nafarroako Unibertsitate Publikoa, 31006.- Pamplona/Iruñea, E-mail: josem.lana@unavarra.es 


\section{RESUMEN}

El objeto de este trabajo es contribuir a un mejor conocimiento de la evolución de la agricultura española del siglo XIX mediante un estudio de caso localizado en el valle medio del Ebro. El cociente entre precios y costes de producción sugiere un avance a largo plazo de la productividad total de los factores (TFP), del orden del 0,42\% anual entre 1792 y 1900 . El avance más destacado se detecta entre 1817 y 1850, coincidiendo con una etapa de deflación y cambio institucional. Durante la segunda mitad del siglo la evolución marcadamente cíclica del indicador refleja las dificultades para resolver los problemas asociados a la oferta de bienes de capital y, en particular, de fertilizantes y tracción animal.

Palabras clave: Productividad total de los factores, Precios agrarios, Costes de producción agraria

A pesar de cuanto se ha escrito acerca de la agricultura española de los siglos XVIII, XIX y XX, la querella entre los historiadores está lejos de haber sido resuelta. De ello dan fe los debates que de cuando en cuando salpican la escena historiográfica española ${ }^{1}$. La imagen dominante hasta la década de 1980 era la de un sector agrario estancado que no había cumplido las tareas que los teóricos del desarrollo atribuyen a la agricultura en el proceso de crecimiento económico, de manera que se prolongaba con un lenguaje actualizado la tradición pesimista del regeneracionismo. El avance de la investigación empírica y la acumulación de series cuantitativas desde los años ochenta modificaron ese panorama, desvelando un sector agrario más dinámico de lo que se había supuesto y reforzando la idea de trayectorias diferenciadas en las regiones españolas ${ }^{2}$.

Desechada de modo definitivo la tesis del estancamiento agrario, la cuestión a dilucidar es si se trató meramente de un crecimiento de tipo extensivo, abocado por tanto a la trampa maltusiana, o de si se puede hablar de crecimiento intensivo. Aunque no se descartan ganancias de productividad derivadas de una creciente especialización regional, predomina la idea de un crecimiento insuficiente y fundamentalmente extensivo, de modo que

1 El debate más animado en la última década ha sido el suscitado por el libro El pozo de todos los males (Pujol et alii, 2001), que dio lugar a seis comentarios en los números 28, 33 y 34 de la revista Historia Agraria, y que ha tenido prolongación en otros libros como El legado económico del Antiguo Régimen en España (Llopis, 2004), El laberinto de la agricultura española (Carmona y Simpson, 2003) y Sombras del progreso (Robledo, 2010).

2 GEHR (1983) (1991); Garrabou y Sanz (1985); Garrabou (1990); Kondo (1990); Simpson (1997); Gallego y Pinilla (1996); Bernal (1999); Calatayud y Martínez Carrión (1999); Bringas (2000); Gallego (2001); Domínguez (2002). 
los añejos argumentos regeneracionistas han sido reciclados en el debate sobre las causas del atraso relativo. Así, se ha discutido la responsabilidad como obstáculos al crecimiento de la geografía y condiciones ambientales, del sistema social y la desigual distribución de la renta, de la dimensión y articulación del mercado interno, de las políticas estatales (y en particular, del proteccionismo triguero) y de las actitudes empresariales. Con todo, la cuestión de si creció la productividad agraria, y cuánto lo hizo, permanece en gran medida abierta ${ }^{3}$.

En este trabajo se plantea revisar este problema desde una perspectiva regional, ceñida a la mitad sur de Navarra. El enfoque localizado es necesario ya que, por un lado, la agricultura española del siglo XIX era intrínsecamente plural, y por otro lado, las posibilidades de lograr avances significativos en una reconstrucción cuantitativa de las variables agrarias con las fuentes disponibles de cobertura estatal parecen poco probables. El objetivo es múltiple. Por un lado, se pretende reconstruir sendas series de índices de evolución de precios agrarios y de costes de los factores de producción. Por otro, se busca combinar esos dos indicadores a través de un cociente que relacione el crecimiento de los precios de productos y el de factores, para ensayar una aproximación -bien conocida en la literatura económica - al concepto de productividad total de los factores (TFP). No se trata tan sólo de replicar los ejercicios realizados para otros países, sino también de testar la validez de un modelo de equilibrio general como es éste en un contexto tan peculiar como la Navarra del siglo XIX ${ }^{4}$.

Téngase en cuenta que, siguiendo a Jorgenson y Griliches, la tasa de crecimiento de la productividad total de los factores presupone una función de producción con retornos constantes a escala, precio de los factores igual a su productividad marginal y tasas de sustitución marginal de bienes igual a sus precios relativos, o lo que es lo mismo, un mercado de competencia perfecta $^{5}$. Cabe, por tanto, desconfiar de la idoneidad de este instrumento aplicado a una sociedad que sólo parcialmente podría ser considerada como una economía de mercado. Sabido es que una parte importante, aunque

3 Pérez Picazo (2006).

4 McCloskey (1975); Hoffman (1991); Allen (1992: 174-179); Clark (1993). La productividad total de los factores es un concepto desarrollado originalmente por Solow y Abramovitz utilizando una función de producción de tipo Cobb-Douglas, y extendido por Jorgenson y Griliches (1967) a una aproximación a través de los precios y costes. Su éxito académico ha venido acompañado también de críticas: se ha señalado que su naturaleza residual hace que además del cambio tecnológico, otros factores - tan aleatorios como el clima - puedan influir en su evolución; también se ha advertido que no es apropiado para captar cambios de naturaleza cualitativa en el crecimiento y que tampoco es capaz de reflejar los costes ambientales del mismo; por último, se ha argumentado que sus supuestos corresponden a un sistema social históricamente muy concreto, el capitalismo de libre mercado, bajo el cual los factores se presentan socialmente diferenciados (Burkett, 2006) (Swartz, 2000) (Grantham, 2000) (Federico, 2005: 74-82) (Persson, 2010: 71-72). Para España, Coll y Bringas (2000).

5 Jorgenson y Griliches (1967: 250). 
imprecisa, de la producción era destinada al autoconsumo (alimento, semilla, piensos) y que en cuanto a los factores, las necesidades de mano de obra eran satisfechas en gran medida por la fuerza de trabajo familiar, mientras que una parte de la tierra permanecía al margen del mercado como bienes vinculados y en manos muertas. Navarra presentaba además algunas particularidades institucionales como su estrecho y rígido marco aduanero y la pervivencia de mecanismos de tasa de precios y jornales. Sin embargo, no es menos cierto que la producción para el mercado era un hecho, incluso entre los pequeños propietarios, inclinados a cultivos comerciales como viñedos y huertas, al tiempo que las estructuras de propiedad de la tierra determinaban la existencia de una amplia bolsa de fuerza de trabajo susceptible de ser contratada a jornal y de un amplio mercado de alquiler de la tierra que, bajo contratos de arrendamiento a corto plazo, podía movilizar un tercio de la superficie cultivada ${ }^{6}$.

En las páginas siguientes se aborda, en primer lugar, la construcción de los dos índices de precios agrarios y coste de los factores. En la segunda sección se muestra la serie de productividad total de los factores que resulta de esos dos índices y se lleva a cabo un test de validez a partir de datos directos de alcance general. En la tercera sección, se contrastan estos resultados con algunos indicadores directos de la evolución de la productividad en algunas explotaciones concretas y se avanzan algunas hipótesis explicativas de la evolución de la curva en sus distintas fases.

\section{TRAMA Y URDIMBRE: LAS SERIES DE ÍNDICES DE PRECIOS AGRARIOS Y COSTE DE LOS FACTORES}

Para calcular la productividad total de los factores debemos contar con series anuales de precios de diferentes productos y factores de producción, así como con sendas matrices de coeficientes de composición del producto y del coste total de producción. Las fuentes utilizadas son algunas contabilidades de patrimonios familiares, corporaciones eclesiásticas, ayuntamientos, carnicerías municipales y fundaciones benéficas. Para el cálculo se puede emplear la fórmula utilizada por Hoffman, que calcula separadamente un índice geométrico ponderado de crecimiento de los precios y otro de los costes, o bien seguir a Clark, que deflacta por separado los índices de evolución de cada uno de los factores como paso previo a su multiplicación. El resultado no varía ${ }^{7}$.

6 De la Torre (1994: 17-101).

7 Hoffman (1996: 84-86); Clark (1999: 239-240). La fórmula que se emplea aquí sigue a Hoffman:

$$
\mathrm{A}=\left(\mathrm{r}^{\mathrm{a}} \mathrm{w}^{\mathrm{b}} \mathrm{s}^{\mathrm{c}}\right) / \mathrm{P}
$$

Siendo A la productividad total de los factores, $\mathrm{P}$ un índice geométrico de crecimiento del precio de los productos agrarios ponderados según su aportación al producto agrario, $\mathrm{r}$ la renta de la tierra, w el 
La primera cuestión que debemos plantearnos es qué mercancías deben entrar a formar parte del índice de precios agrarios y en qué proporción, para lo cual contamos con algunas informaciones sobre el producto agrícola en la comarca (cuadro 1). Aunque la fiabilidad de estas fuentes es muy desigual y las cifras globales que algunas de ellas ofrecen no merecen ninguna confianza, nos pueden servir, pese a todo, para dibujar la estructura interna del valor agrícola bruto $(\mathrm{VaB})^{8}$. Interesa destacar la relativa estabilidad en su composición durante la primera mitad del siglo y la alteración atestiguada desde 1854, cuando el vino pasó de suponer una cuarta parte del producto hasta alcanzar en la década de 1880 la mitad del mismo. El auge vitivinícola experimentado hasta 1896 (fecha en que fue declarada la epidemia de filoxera en la provincia) implicó una inversión en el peso relativo de los cultivos de ciclo anual respecto a los permanentes, en el que el vino reemplazó al trigo como producto principal. Algunas de estas fuentes ofrecen además información sobre producciones ganaderas, que nos permiten cifrar en un doce por cien su participación en el total del producto agrario ${ }^{9}$. Teniendo en cuenta estos cambios en la composición del producto se propone aquí un doble índice de precios agrarios y coste de los factores, empalmando dos índices geométricos de ponderaciones fijas en el año base 1856. Dada la estructura productiva que muestra el cuadro 1, contar con series de precios de nueve mercancías - trigo, cebada, alubias, patata, vino, aceite de oliva, carne de vaca, carnero y lana - nos permite dar cobertura a más del noventa por cien del producto agrario ${ }^{10}$.

Por el lado del denominador han de tomarse igualmente decisiones acerca de las proporciones asignadas a los diferentes factores dentro del coste de producción. Para comienzos del siglo XX contamos con un conjunto de cartillas evaluatorias de extraordinaria calidad, que fueron confeccionadas por ingenieros en nómina de la Diputación provincial tras un exhaustivo trabajo de campo (cuadro 3). A falta de mejores fuentes para el siglo XIX, y habida cuenta del peso abrumador de los procedimientos manuales y del escaso contenido tecnológico que sugiere el utillaje descrito en estas cartillas, se propone tomar estos datos como base para ponderar la estructura del coste de los factores durante el siglo XIX. Esto no significa que

\footnotetext{
(F'note continued)

salario, y s la remuneración del capital, siendo a, b y c los coeficientes de ponderación de cada factor en el coste total.

${ }^{8}$ Los precios utilizados para valorar la producción corresponden al partido judicial de Tudela durante el quinquenio 1853-1857: Trigo (23,1 pts/hl), cebada (12,4 pts/hl), avena (10,7 pts/hl), centeno (16 pts/hl), maíz (13,3 pts/hl), legumbres (29,3 pts/hl), vino común (25,5 pts/hl), aceite de oliva $(91,5 \mathrm{pts} / \mathrm{hl})$, aguardiente $(42,5 \mathrm{pts} / \mathrm{hl})$, patatas $(37,3 \mathrm{pts} / \mathrm{tm})$, remolacha $(74,7 \mathrm{pts} / \mathrm{tm})$, lino (933,4 pts/tm) y cáñamo (896,1 pts/tm) (Sanz Baeza, 1859: 98-101).

9 Con los datos de la estadística de 1803-07 la producción de carne representaría un 5\% del producto agrario bruto y la de lana un 7\% (AGN, Reino, Estadística, lg.49).

${ }^{10}$ Deben entenderse como series anuales por años contables de precios ponderados al por mayor.
} 


\section{CUADRO 1}

COMPOSICIÓN DEL PRODUCTO AGRÍCOLA EN LA COMARCA DE TUDELA DE NAVARRA, 1800-1906

(Datos en porcentaje sobre el producto agrícola bruto valorado a los precios medios del quinquenio 1853-1857)

\begin{tabular}{|l|r|r|r|r|r|r|r|r|}
\hline Producto & $\mathbf{1 8 0 0}$ & $\mathbf{1 8 0 2 - 0 6}$ & $\mathbf{1 8 1 8}$ & $\mathbf{1 8 4 9 - 5 4}$ & $\mathbf{1 8 5 7}$ & $\mathbf{1 8 7 8}$ & $\mathbf{1 8 8 2 - 9 0}$ & $\mathbf{1 9 0 3 - 0 6}$ \\
\hline Trigo & 48,5 & 42,9 & 41,5 & 46,9 & 32,5 & 28,9 & 25,9 & 39,9 \\
\hline Centeno & 1,5 & 1,1 & 1,5 & 0,9 & 1,9 & 0,0 & 0,2 & 0,3 \\
\hline Cebada & 11,8 & 10,7 & 10,6 & 7,1 & 9,7 & 5,5 & 4,8 & 13,4 \\
\hline Avena & 1,2 & 1,1 & 2,4 & 1,6 & 2,7 & 1,6 & 0,6 & 2,4 \\
\hline Maíz & 0,0 & 0,5 & 1,1 & 1,4 & 0,0 & 3,2 & 2,0 & 4,0 \\
\hline Aceite de oliva & 12,3 & 8,2 & 19,2 & 14,0 & 19,7 & 14,6 & 11,4 & 14,7 \\
\hline Vino & 17,4 & 25,0 & 23,3 & 23,0 & 26,5 & 42,0 & 51,4 & 0,0 \\
\hline Aguardiente & $\mathrm{Nd}$ & 3,0 & $\mathrm{Nd}$ & 2,4 & $\mathrm{Nd}$ & 1,4 & $\mathrm{Nd}$ & $\mathrm{Nd}$ \\
\hline Legumbres & 2,7 & 3,4 & 0,0 & 2,6 & 4,4 & 0,9 & 1,6 & 2,0 \\
\hline Patatas & 0,0 & 0,0 & 0,5 & $\mathrm{Nd}$ & 0,7 & 0,6 & 1,1 & 1,6 \\
\hline Remolacha & 0,0 & 0,0 & 0,0 & 0,0 & 0,0 & 0,0 & 0,0 & 21,5 \\
\hline Lino & 0,3 & 0,5 & $\mathrm{Nd}$ & $\mathrm{Nd}$ & 0,2 & 0,0 & 0,0 & 0,0 \\
\hline Cáñamo & 4,2 & 3,7 & $\mathrm{Nd}$ & $\mathrm{Nd}$ & 1,8 & 1,3 & 1,0 & 0,2 \\
\hline Suma & $\mathbf{1 0 0}$ & $\mathbf{1 0 0}$ & $\mathbf{1 0 0}$ & $\mathbf{1 0 0}$ & $\mathbf{1 0 0}$ & $\mathbf{1 0 0}$ & $\mathbf{1 0 0}$ & $\mathbf{1 0 0}$ \\
\hline VaB (millones pts) & 5,11 & 4,08 & 3,38 & 4,08 & 8,05 & 7,84 & 10,29 & 11,88 \\
\hline
\end{tabular}

Fuentes: 1800 (Lana, 1999: 142-146); 1802-06 (AGN, Reino, Estadística, legajo 49); 1818 (Yanguas y Miranda, 1828: 171-173); 1849-54 (Archivo Municipal de Tudela, Catastro); 1857 (estimación a partir de Sanz Baeza, 1859, pp.83-95); 1878 (AAN, DFN, cj. 40.979); 1882-90 (JCA, 1891a, 1891b, 1891c); 1903-06 (Lana, 1999: 147-151)

Notas: VaB: Producto agrícola bruto valorado a los precios medios del quinquenio 1853-1857 y expresado en millones de pesetas.

no se produjeran algunos cambios técnicos o que la propia estructura de costes no se modificase al cambiar las proporciones entre cultivos herbáceos y leñosos. Teniendo en cuenta esto último y aplicando los porcentajes correspondientes a cada producto que obran en el cuadro 2, se han obtenido dos matrices de ponderaciones aplicables a los periodos anterior y posterior al año $1856^{11}$.

11 Se ha considerado que tres cuartas partes de la producción de cereales, aceite y vino correspondían hacia 1800 a cultivo de regadío y el 25 por cien restante a secano. Tras un siglo de extensión del cultivo y colonización interior de terrenos de secano se ha considerado que hacia 1880 el cultivo de regadío aportaba tan sólo dos terceras partes del producto de cereales y oliva y la mitad del vino, atribuyendo el resto al cultivo de secano. 
CUADRO 2

PONDERACIONES DEL ÍNDICE DE PRECIOS AGRARIOS, 1780-1900

\begin{tabular}{|l|c|c|}
\hline & $\mathbf{1 7 8 0 - 1 8 5 6}$ & $\mathbf{1 8 5 6 - 1 9 0 0}$ \\
\hline Trigo & 0,42 & 0,25 \\
\hline Cebada & 0,13 & 0,08 \\
\hline Alubias & 0,03 & 0,02 \\
\hline Vino & 0,20 & 0,40 \\
\hline Aceite de oliva & 0,10 & 0,12 \\
\hline Patatas & 0 & 0,01 \\
\hline Vaca & 0,02 & 0,02 \\
\hline Carnero & 0,03 & 0,03 \\
\hline Lana & 0,07 & 0,07 \\
\hline Total & $\mathbf{1 , 0 0}$ & $\mathbf{1 , 0 0}$ \\
\hline
\end{tabular}

Fuente: Elaborado a partir de CUADRO 1

El resultado se ofrece en el cuadro 4, al lado de un conjunto de ponderaciones utilizadas por otros autores en ejercicios similares. Lo que pone de relieve este contraste es, en primer lugar, la validez de los coeficientes propuestos para Navarra, que se mantienen lejos de los valores extremos, y en segundo lugar, la cautela con que debemos abordar el uso comparativo de las cifras resultantes de estos ejercicios dadas las diferencias existentes a la hora de establecer las ponderaciones.

El paso siguiente es el de reunir las series a las que se han de aplicar estos coeficientes de ponderación. El jornal diario común del peón de campo se ha escogido como representativo de los salarios, de modo que contamos con una serie homogénea en cuanto a la cualidad del trabajador y la duración de la jornada ${ }^{12}$. En el caso de la simiente se ha optado por emplear como indicador la serie de precios del trigo que forma parte ya del índice de precios agrarios. La serie referida al coste del equipo de tracción animal se ha podido elaborar gracias a las abundantes anotaciones de alquiler diario de yuntas que figuran en las cuentas de explotación, escogiéndose los datos referidos a la yunta de dos mulas (y desechando las de bueyes y asnos o tres o más animales) a fin de obtener una serie homogénea. El jornal de la yunta

12 No se tienen en cuenta las remuneraciones de otro tipo de trabajadores, como mujeres o muchachos, criados fijos, especialistas o las jornadas de sol a sol de siega y trilla. El componente no monetario del salario, reducido a un jarro de vino por peón, se ha traducido a dinero usando la serie de precios del vino común (Martínez Carrión, 2002: 183-233). 
CUADRO 3

PARTICIPACIÓN DE LOS FACTORES EN EL COSTE DE CULTIVO EN EL SUR DE NAVARRA HACIA 1905.

\begin{tabular}{|l|c|c|c|c|c|c|c|c|}
\hline & Renta & Salarios & Tracción & Semillas & Abonos & Agua & Otros & $\begin{array}{c}\text { Coste } \\
\text { total }\end{array}$ \\
\cline { 2 - 9 } & $\%$ & $\%$ & $\%$ & $\%$ & $\%$ & $\%$ & $\%$ & Ptas/Ha \\
\hline Huerta & 22,7 & 35,9 & 4,1 & 11,4 & 21,3 & 2,2 & 2,4 & 1.141 \\
\hline Pimiento & 9,7 & 35,8 & 5,7 & 24,4 & 20,4 & 1,6 & 2,5 & 1.435 \\
\hline Cáñamo & 21,4 & 35,8 & 10,7 & 8,0 & 21,4 & 0,2 & 2,4 & 1.040 \\
\hline Patata & 20,4 & 32,0 & 8,3 & 17,6 & 16,0 & 1,7 & 4,1 & 765 \\
\hline Alcachofa & 19,4 & 43,9 & 4,6 & 7,0 & 19,4 & 3,2 & 2,5 & 716 \\
\hline Remolacha & 15,5 & 39,0 & 25,1 & 0 & 14,3 & 3,5 & 2,6 & 534 \\
\hline Alfalfa & 29,6 & 28,1 & 10,6 & 2,1 & 14,8 & 2,6 & 12,2 & $* 530$ \\
\hline Judías & 20,3 & 37,1 & 8,1 & 23,8 & 3,9 & 3,6 & 3,2 & 467 \\
\hline Maíz & 21,7 & 26,8 & 27,6 & 1,7 & 11,9 & 5,8 & 4,4 & 449 \\
\hline Habas & 31,9 & 28,9 & 7,6 & 8,2 & 15,9 & 3,8 & 3,6 & 439 \\
\hline Trigo Regadío & 24,4 & 24,8 & 24,2 & 10,4 & 5,3 & 4,0 & 6,9 & 416 \\
\hline Cebada Regadío & 28,1 & 24,6 & 23,6 & 6,8 & 6,4 & 3,6 & 6,9 & 386 \\
\hline Avena Regadío & 24,2 & 27,1 & 29,5 & 5,2 & 0 & 5,7 & 8,2 & 322 \\
\hline Trigo Secano & 2,6 & 33,0 & 37,3 & 21,3 & 0 & 0 & 5,8 & 148 \\
\hline Cebada Secano & 3,4 & 34,7 & 41,5 & 13,4 & 0 & 0 & 7,1 & 132 \\
\hline Avena Secano & 2,6 & 35,0 & 44,8 & 10,4 & 0 & 0 & 7,1 & 129 \\
\hline Olivar Regadío & 25,7 & 37,8 & 11,5 & 0 & 7,5 & 1,4 & 16,1 & 328 \\
\hline Olivar Secano & 22,4 & 33,2 & 15,8 & 0 & 11,4 & 0 & 17,2 & 190 \\
\hline Viña Regadío & 26,6 & 37,9 & 6,5 & 4,5 & 9,0 & 2,1 & 13,5 & 317 \\
\hline Viña Secano & 21,3 & 47,4 & 5,0 & 6,5 & 6,6 & 0 & 13,1 & 200 \\
\hline Plantados de vid & 1,9 & 35,1 & 19,5 & 14,7 & 25,9 & 0 & 2,8 & $* 429$ \\
\hline
\end{tabular}

Fuentes: Cartillas evaluatorias confeccionadas y firmadas por el ingeniero agrónomo Florencio Roldán para Tudela (24-10-1905) y Cascante (31-8-1906), AGN, DFN, Catastro, cjs.16133-16151. Para el caso del viñedo se han manejado las cartillas evaluatorias de 1890 de Fustiñana, Tulebras, Ribaforada, Murillo el Cuende, Murillo el Fruto y Milagro. AGN, DFN, Catastro, cj. 16.131

Notas: *.- promedio de 6 años para la alfalfa; promedio de 3 años para los plantados de vid. 
CUADRO 4

PONDERACIONES DE LOS FACTORES DE PRODUCCIÓN EN EL COSTE TOTAL DE CULTIVO SEGÚN DIFERENTES AUTORES Y PROPUESTA PARA EL SUR DE NAVARRA.

\begin{tabular}{|c|c|c|c|c|c|c|c|c|c|c|}
\hline Autor & \multicolumn{2}{|c|}{ Lana } & Hoffman & Grantham & Allen & Clark & Gallman & Knibbe & $\begin{array}{c}\text { Reis \& } \\
\text { Fonseca }\end{array}$ & Bringas \\
\hline \begin{tabular}{|l|} 
Lugar \\
\end{tabular} & \multicolumn{2}{|c|}{ Sur Navarra } & Francia & Francia & Inglaterra & Inglaterra & EEUU & Holanda & Portugal & España \\
\hline Época & $1782-1856$ & $1856-1900$ & 1765 & 1870 & 1770 & $\begin{array}{l}1700- \\
1860\end{array}$ & 1860 & $1799-1810$ & s.XIX & s.XIX-XX \\
\hline $\begin{array}{r}\text { Renta de } \\
\text { la tierra }\end{array}$ & 0,24 & 0,24 & 0,27 & 0,33 & 0,40 & 0,40 & 0,17 & 0,28 & 0,33 & 0,16 \\
\hline Salarios & 0,35 & 0,41 & 0,36 & 0,35 & 0,27 & 0,40 & 0,70 & 0,33 & 0,24 & 0,16 \\
\hline $\begin{array}{c}\text { Tracción } \\
\text { animal }\end{array}$ & 0,22 & 0,17 & 0,06 & & & & & & & 0,34 \\
\hline Simiente & 0,11 & 0,09 & 0,20 & 0,32 & 0,13 & 0,20 & 0,13 & 0,40 & 0,43 & 0,18 \\
\hline Abonos & 0,08 & 0,09 & & & & & & & & 0,12 \\
\hline Otros & 0 & 0 & 0,11 & & 0,20 & & & & & 0,04 \\
\hline
\end{tabular}

Fuentes: Hoffman (1996: 215); Grantham (1996: 58); Allen (1992: 226); Clark (1999: 230); Gallman (1972: 205); Knibbe (2006); Fonseca y Reis (2011); Bringas (2000: 146); CUADRO 3. 
remunera el equipo de tracción en su conjunto, de modo que al lado de la fuerza de tiro animal se incluyen implícitamente los piensos necesarios para alimentarla, los cuidados veterinarios, herraje y esquileo, y el equipamiento (desde los atalajes a los remolques y arados), pero también incorpora la remuneración del factor trabajo correspondiente al conductor, por cuya razón se ha descontado del jornal de yunta el importe del salario diario del peón de campo ${ }^{13}$.

Más complicado es construir un índice de coste de los fertilizantes. Siendo escasas y discontinuas las menciones a la compra de estiércol en las contabilidades privadas, se ha optado por una vía indirecta, aprovechando la anotación en las cuentas de ayuntamientos y carnicerías municipales de lo obtenido en las subastas del aprovechamiento del estiércol de los corrales de su propiedad. El inconveniente de la serie radica en que el arrendador de los fiemos podría no coincidir con el usuario de los mismos, y que por tanto no se trataría de precios al agricultor, sino de precios obtenidos por el intermediario. También hay que tener en cuenta que el precio de subasta puede en ocasiones reflejar, no la cotización del estiércol, sino la cantidad del mismo que cabía esperar obtener durante el periodo de arriendo habida cuenta del número de cabezas que se preveía alojarían los corrales. No obstante, los datos disponibles sobre el precio del estiércol por unidad de peso confirman en términos generales el movimiento de la curva ${ }^{14}$.

La última serie, la de la renta de la tierra, es la que presenta mayor complejidad. Lo habitual es encontrar en la documentación contable rentas pagadas en una cantidad estipulada de trigo por tierras de labor de regadío y secano. Las rentas en metálico son menos frecuentes, quedando circunscritas al alquiler de huertas, viñedos y pastos. Se ha seguido por ello la opción de construir nueve series de renta en especie con diferente recorrido temporal que han sido transformadas a números índices como paso previo a su empalme. Luego se ha traducido ese índice a términos físicos expresados en hectolitros por hectárea teniendo en cuenta la renta media que ofrecen siete series en $1859(4,14 \mathrm{hls} / \mathrm{ha})^{15}$. Sobre esa serie se han calculado dos

13 Efectuado ese descuento, se comprueba que el coste de la fuerza de tracción (109 por cien) creció más de lo que sugiere el jornal completo de yunta y peón (85 por cien).

14 Se han recopilado los arriendos de fiemos de corrales de los municipios de Andosilla, Arguedas, Carcastillo, Cortes, Mélida, San Adrián y Villafranca y de la carnicería municipal de Pamplona. Resulta difícil obtener una serie homogénea de información tan variada, ya que muchos de los arriendos se limitan a unos pocos años o presentan niveles y cuantías demasiado diversos. Por ello se han construido catorce series con un grado razonable de homogeneidad, expresadas como números índice con base cien en el año común 1856. Se ha separado el arriendo de los corrales de las dehesas (destinados al ganado lanar) de los de la dula (ocupados por los ganados de labor) y de los de la carnicería municipal. Allá donde también se arrendaba el aprovechamiento de las basuras de las calles (Arguedas) y de los limos de las acequias (San Adrián) se han tratado separadamente. La coherencia de esta serie con los datos disponibles de precio del estiércol puede comprobarse en Garrabou y González de Molina (2010: 247-248)

${ }^{15}$ Las nueve series corresponden a la familia Goñi en Corella (1795-1874), los marqueses de San Adrián en Monteagudo (1800-1900), Tulebras (1841-1900) y San Adrián (1823-1900), el conde 
variaciones. La primera resulta de aplicar hasta 1840 un aumento del 12,5 por cien en concepto de diezmo y primicia. La segunda eleva esa cuantía tomando en cuenta las contribuciones ordinarias y extraordinarias, utilizando como referencia las pagadas por los marqueses de San Adrián en proporción a sus ingresos ${ }^{16}$. Disponemos así de tres series alternativas de renta de la tierra que se pueden emplear en el ejercicio. En la medida en que las contribuciones al Estado corrían mayoritariamente a cuenta del propietario, se entiende aquí que esta exacción de renta agraria va ya incluida en la propia renta del suelo. No así en el caso del diezmo, que se superponía hasta 1840 sobre esa detracción. La serie que se empleará aquí, por tanto, es la que suma renta y diezmo, transformada a su valor monetario con la serie de precios del trigo como multiplicador.

\section{ACCELERANDO ... RITARDANDO. EL TEMPO DE LA PRODUCTIVIDAD TOTAL DE LOS FACTORES EN EL SUR DE NAVARRA, 1782-1900}

Reunidas todas las piezas del puzzle, podemos aplicar la fórmula para estimar la productividad total de los factores. Tras estos cálculos se esconde una intuición relativamente simple: una mayor productividad también significa producir a un coste menor. Esto puede traducirse inicialmente en mayores beneficios para los agricultores más productivos, pero conducirían finalmente bien a rentas superiores para los terratenientes, bien a salarios más altos para los trabajadores agrícolas, bien a remuneraciones superiores para el capital agrícola, o bien a precios más bajos para los consumidores.

Los resultados pueden observarse en el gráfico 1, donde se recogen también la evolución del índice de precios del producto agrario y la del coste

\footnotetext{
(F'note continued)

de Zaldívar en Cortes y Buñuel (1859-1888), la marquesa viuda de Rafol y su hijo el marqués de Malferit en Sartaguda (1831-43; 1847-48; 1851-59), el Hospital de Gracia de Tudela (1780-1843), la parroquia de La Magdalena de Tudela (1780-1821) y el Monasterio de La Oliva (1815-1834). La superficie en arriendo abarca en conjunto más de 1.400 hectáreas. Se han construido dos índices promediados: uno con base cien en 1815 para las series presentes entre 1780 y 1840 , y otro con base cien en 1859 para las series disponibles en la segunda mitad del siglo. El empalme de ambos índices se ha efectuado en 1831, cuando coinciden cinco observaciones en cada uno de ellos. Hay que indicar que se trata de la renta contractual y no de la efectivamente cobrada, ya que no se han considerado los atrasos en el pago. Agradezco a Antonio López Estudillo sus comentarios al manejo de estas series.

16 El administrador de la familia Goñi advertía en 1842: "El aumento que se observa en este año y se observará en los siguientes en las rentas de 2 almudes en cada robo de trigo proviene de la supresión del diezmo, que antes pagaban íntegro los inquilinos y ahora pagan en su mayor parte los propietarios en la contribución de culto y clero sustituida al diezmo". Los dos almudes por robo de trigo equivalen exactamente a un 12,5 por cien. (AGN, Arteta, caja 16, carpeta 49, año 1842). Se ha normalizado la serie que suma el diezmo trazando una interpolación lineal para los años 1841, 1842 y 1843 .
} 


\section{GRÁFICO 1}

ÍNDICES DE EVOLUCIÓN DE PRECIOS AGRARIOS Y COSTE DE LOS FACTORES

EN EL SUR DE NAVARRA, 1782-1900

(datos anuales, índice $100=1856)$

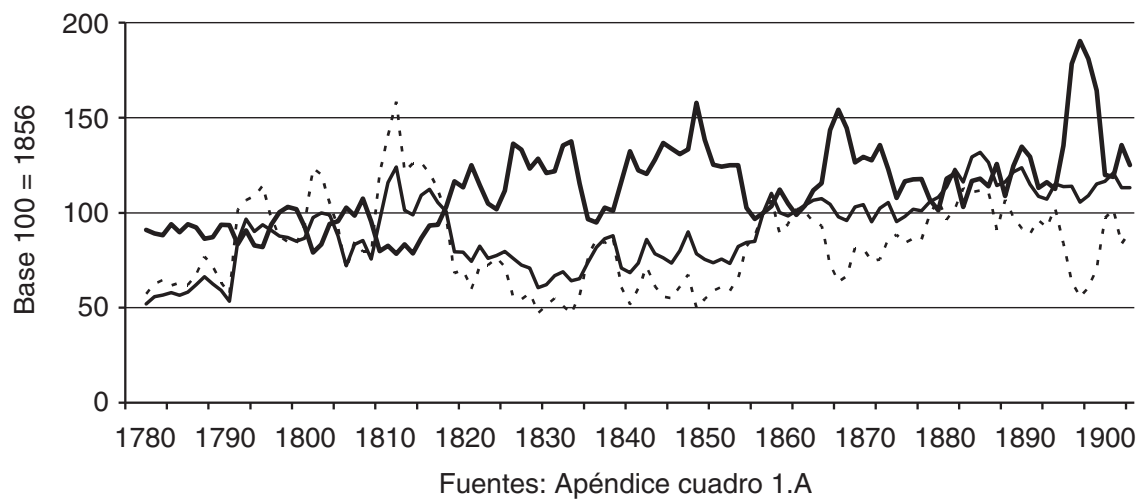

.... índice Precios - índice Costes TFP

de producción. Los datos, de carácter anual, se presentan como números índices con base cien en el año 1856. Es fácil detectar a simple vista la relación existente entre el signo de la dinámica de precios y la dirección de la serie que identificamos con la productividad total de los factores. Durante el periodo inflacionario de las guerras de la Revolución y el Imperio francés (1792-1814), la serie TFP sigue una dirección a la baja, del mismo modo que ocurre durante la etapa de aumento de precios de la primera guerra carlista (1833-39) o durante los ciclos alcistas de 1854-64 y 1875-85. Por el contrario, las etapas de deflación de precios se saldan con importantes avances de la serie TFP, en particular entre 1815-1833, 1861-1866 y 1891-1895. La relación es más evidente si disponemos las series en forma de medias móviles de once años como se hace en el gráfico $2^{17}$. Para mostrar de manera más clara la evolución de estas tres series a lo largo del tiempo se ha modificado el año base, de manera que los índices se refieren en este gráfico a la media aritmética de los años 1782-1792. La relación inversa entre la curva TFP y la de precios agrarios se revela prácticamente perfecta, y la inevitable pregunta

17 Hay que tener especial cuidado con la elección del grosor temporal de la media móvil. Aquí se ha escogido la de once años porque facilita la visión de largo plazo y porque coincide en su resultado con el obtenido con medias de siete, trece y quince años $(0,42 \%)$. Con medias móviles de cinco años, sin embargo, el resultado sería de 0,34 por cien, con nueve años subiría hasta 0,46 y con 19 años se situaría en 0,38 por cien. 


\section{GRÁFICO 2}

ÍNDICES DE EVOLUCIÓN DE PRECIOS AGRARIOS, COSTE DE LOS FACTORES Y

TFP EN EL SUR DE NAVARRA, 1782-1900

(medias móviles de 11 años, base $100=1782-1792$ )

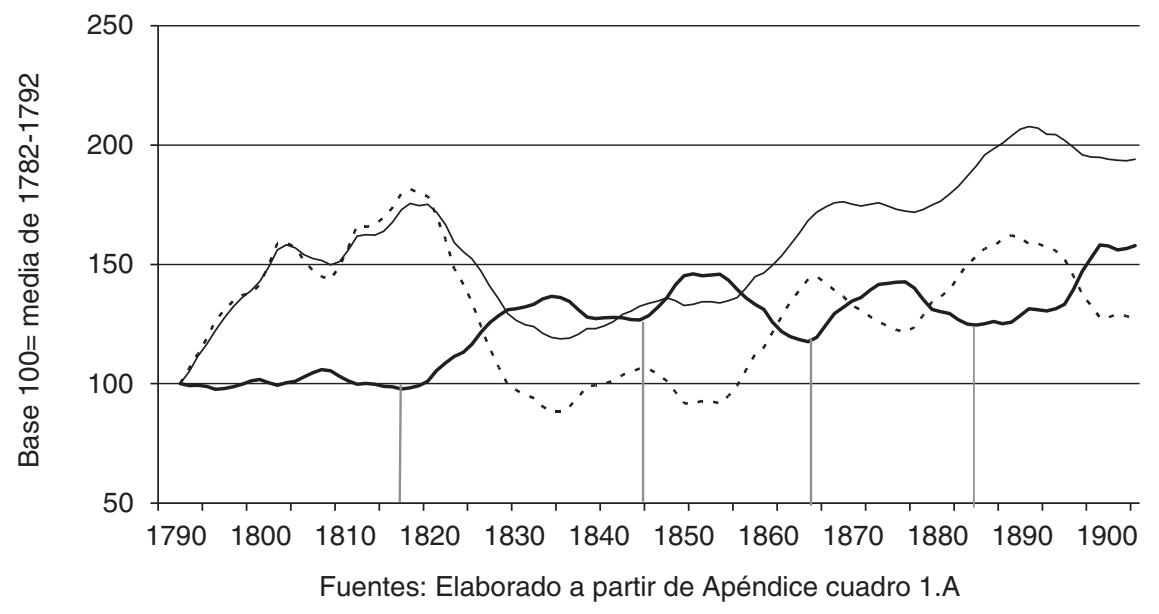

-... índice Precios — índice Costes — TFP (mm 11a)

es: ¿Refleja efectivamente la curva TFP una mejora en la eficiencia productiva o tan sólo nos está indicando el margen entre precios percibidos y precios pagados en que se mueve el productor?

En el corto plazo no cabe duda de que la serie indica, de manera inversa, cómo evoluciona la rentabilidad de las explotaciones. La formación de los precios de los productos agrarios se verifica en un marco más abierto y fluido, lo que les confiere una mayor volatilidad, mientras que los precios de los factores, en especial los de la fuerza de trabajo y los de la tierra, necesitan más tiempo para ajustarse. De modo que a corto plazo la serie depende de los movimientos que experimentan los precios agrarios. Pero también es cierto que, observado en el largo plazo, el gráfico está reflejando necesariamente una mejora en el uso de los factores. Si el coste de éstos creció entre 1792 y 1900 a un ritmo anual del 0,61 por cien (cuadro 5) y los precios agrarios tan sólo aumentaron a razón de un 0,23 por cien por año, es inevitable pensar que las explotaciones que operaban en 1900 eran mucho más productivas que las de cien años atrás ${ }^{18}$.

${ }^{18}$ La adición de las contribuciones estatales a la suma de renta de la tierra y diezmo (como se puede comprobar en la CUADRO 5) no modifica sustancialmente el resultado. 


\section{CUADRO 5}

TASAS DE CRECIMIENTO ANUAL (\%) DE PRECIOS AGRARIOS Y COSTES DE LOS FACTORES EN EL SUR DE NAVARRA, 1792-1900

(estimados a partir de medias móviles de 11 años fechadas en el último)

\begin{tabular}{|c|c|c|c|c|c|c|c|c|}
\hline & $\begin{array}{c}1792- \\
1900\end{array}$ & $\begin{array}{c}1792- \\
1817\end{array}$ & $\begin{array}{l}1817- \\
1844\end{array}$ & $\begin{array}{c}1844- \\
1863\end{array}$ & $\begin{array}{c}1863- \\
1882\end{array}$ & $\begin{array}{l}1882- \\
1900\end{array}$ & $\begin{array}{c}1792- \\
1863\end{array}$ & $\begin{array}{c}1863- \\
1900\end{array}$ \\
\hline Trabajo & 0,55 & 1,75 & $-0,80$ & 1,16 & 1,04 & $-0,23$ & 0,62 & 0,42 \\
\hline Tierra & 0,70 & 2,87 & $-1,66$ & 1,70 & 0,86 & 0,03 & 0,83 & 0,45 \\
\hline Capital & 0,60 & 2,22 & $-0,78$ & 1,02 & 0,11 & 0,50 & 0,76 & 0,30 \\
\hline Yuntas & 0,65 & 2,42 & $-0,91$ & 0,42 & 0,23 & 1,19 & 0,62 & 0,70 \\
\hline Semilla & 0,39 & 2,50 & $-1,72$ & 1,29 & 0,14 & $-0,06$ & 0,57 & 0,04 \\
\hline Fertilizantes & 0,80 & 1,56 & 0,53 & 2,12 & $-0,18$ & $-0,24$ & 1,32 & $-0,21$ \\
\hline Costes & 0,61 & 2,19 & $-0,99$ & 1,27 & 0,66 & 0,09 & 0,73 & 0,38 \\
\hline Precios & 0,23 & 2,34 & $-1,94$ & 1,59 & 0,34 & $-1,03$ & 0,51 & $-0,32$ \\
\hline TFP & 0,42 & $-0,09$ & 0,96 & $-0,40$ & 0,30 & 1,32 & 0,23 & 0,80 \\
\hline TFP (ii) & 0,46 & 0,03 & 0,97 & $-0,45$ & 0,43 & 1,28 & 0,26 & 0,84 \\
\hline
\end{tabular}

Fuentes: Vid.anexo

Notas: (ii) Se ha calculado, a efectos meramente informativos, una serie alternativa de TFP incluyendo junto a la renta de la tierra y el diezmo las contribuciones, aunque en esta región éstas quedaban por regla general a cargo del propietario.

Ahora bien, ¿Cómo debemos interpretar ese 0,42 por cien anual de crecimiento de la TFP en el sur de Navarra entre 1792 y 1900? ¿Es mucho o es poco? La búsqueda de términos de comparación ha de hacerse con suma cautela. Como ya se ha señalado, pese a la aparente similitud de los índices TFP con los que contamos, la diversidad de métodos de cálculo empleados (productos, precios y ponderaciones elegidas) puede llevarnos a comparar cosas distintas. Limitémonos a señalar que el dato de Navarra coincide a grandes rasgos con la estimación que realizó Bringas para el conjunto de España con distinta ponderación de factore ${ }^{19}, \mathrm{y}$ también que podría situarse en una posición intermedia entre los pobres resultados del Alentejo portugués y las tasas estimadas para algunas regiones de Francia y Gran Bretaña $^{20}$. Más que la cuantía de la tasa, quizás resulte revelador contrastar

19 Este autor cifró en un 0,49 por cien la tasa anual de incremento entre 1800 y 1905 . El crecimiento habría sido más intenso después de 1857 (0,95 por cien) que antes de esa fecha $(0,16$ por cien) (Bringas, 2000: 149), lo cual no desentona con las tasas anteriores y posteriores a 1863 del CUADRO 5.

${ }^{20}$ Fonseca y Reis (2011). Sutherland encuentra que la TFP se triplicó entre 1800 y 1914 en la zona de Le Mans, con ganancias más modestas en Rouen y Compiègne (Sutherland, 2003) (Le Goff 
los movimientos y tendencias de la curva que dibuja la TFP en distintas regiones. Y en este sentido hallamos una cierta coincidencia entre regiones tan diferentes como las Midlands inglesas estudiadas por Allen, la Frisia analizada por Knibbe, el Rouen de Le Goff y Sutherland y el Alentejo de Fonseca y Reis, donde se percibe, con diferencias de grado e intensidad, un deterioro de la TFP en las dos últimas décadas del siglo XVIII y la primera del XIX, seguido de un impulso ascendente tras las guerras napoleónicas, que en el caso inglés alcanzó al 3,4 por cien anual entre 1814 y $1838^{21}$.

El cuadro 5 incluye también las tasas de crecimiento anual de estas variables para cinco subperiodos definidos por otros tantos ciclos que se detectan en el recorrido de la serie TFP. Hay que destacar que se toman como punto de partida y llegada de cada etapa los valores mínimos de estos ciclos $(1817,1844,1863$ y 1882), desechando las cimas (1834, 1850, 1874). De este modo se evita sobrevalorar el crecimiento de la productividad, al tomar como referencia los sucesivos suelos por debajo de los cuales ya no vuelve a descender la curva. Así, en lugar de destacar el intenso crecimiento de la serie TFP entre 1817 y 1834 (dos por cien anual), nos quedamos con una tasa más modesta pero segura del $0,96 \%$ anual entre la primera fecha y 1844 . El cuadro permite además detectar qué factores respondieron mejor a los estímulos del crecimiento y cuáles mostraron mayor rigidez, entorpeciendo su avance. Entre estos últimos debemos incluir los fertilizantes, cuyo coste creció a un ritmo del 0,80 por cien anual, por encima del coste de alquiler de la tierra $(0,70$ por cien por año) y del equipo de tracción $(0,65$ por cien), y a gran distancia del factor trabajo (0,55 por cien) y de la semilla de trigo (0,39 por cien).

Con el fin de validar los datos obtenidos, podemos ensayar un test a partir de cifras aportadas por otras fuentes. Los resultados, que se circunscriben a la comarca de Tudela, se sintetizan en el cuadro 6. A partir de información de origen catastral se ha estimado tanto la superficie cultivada como la fuerza de tracción animal (expresada en peso en vivo) y el estiércol disponible ${ }^{22}$. En

\section{(F'note continued)}

y Sutherland, 2000: 300-308). Para Gran Bretaña Crafts (1985: 83-85) propuso un aumento del 0,6 por cien anual durante el siglo XVIII, que Allen (2004: 132-133) elevó al 0,9 por cien anual entre 1780 y 1850. Clark (1993) (1999) ha revisado a la baja estos cálculos, reduciendo el aumento de la TFP a menos del 25 por cien entre 1700 y 1860. Una renovada defensa del enfoque tradicional a partir de estimaciones directas de la productividad se hallará en Overton \& Campbell (1999).

21 Allen (2004: 132-133); Knibbe (2006); Le Goff y Sutherland (2000: 304); Fonseca y Reis (2011).

${ }^{22}$ Se ha atribuido a 1800 el dato obtenido del catastro mandado confeccionar por las Cortes del Reino en 1817-18 (Lana, 1999). Además de la probable ocultación, el principal problema radica en que las huellas de la guerra napoleónica sobre la cabaña ganadera eran todavía muy visibles. Las manifestaciones de frutos y manufacturas redactadas por el ayuntamiento de Corella a instancias de la Corona permiten comprobar el retraso en la recomposición de la cabaña mular, que se mantuvo entre 1814 y 1819 en torno a un cuarenta por cien del número de cabezas existentes entre 1799 y 1807, cuando la cabaña ovina se había recompuesto ya para 1816 (Lana, 1999:69). Por ello se ha rectificado el número de caballerías mayores, elevándolo en un sesenta por cien. La cifra de 1900 es 


\section{CUADRO 6}

ESTIMACIÓN DE LAS TASAS DE CRECIMIENTO ANUAL DE LA DOTACIÓN DE FACTORES Y DE LA TASA ESPERABLE DE INCREMENTO DEL PRODUCTO PARA LA COMARCA DE TUDELA, 1800-1900

\begin{tabular}{|c|c|c|c|c|}
\hline \multicolumn{2}{|c|}{ Cantidad de factores } & 1800 & 1900 & Tasa $(\%)$ \\
\hline Superficie cultivada & Hectáreas (miles) & 22,8 & 54,2 & 0,87 \\
\hline Población & Personas (miles) & 28,5 & 49,4 & 0,55 \\
\hline Ganado de labor (peso en vivo) & Quintales métricos (miles) & 9,8 & 16,8 & 0,54 \\
\hline Semilla de trigo & Hectolitros (miles) & 21,5 & 21,4 & $-0,00$ \\
\hline Estiércol & Toneladas métricas (miles) & 99,7 & 103,3 & 0,04 \\
\hline \multicolumn{4}{|c|}{ Tasa ponderada de crecimiento de la cantidad de factores: } & 0,60 \\
\hline \multicolumn{4}{|c|}{$\begin{array}{l}\text { Tasa de crecimiento de la productividad total de los factores 1790-1900 } \\
\text { (medias móviles 11años): }\end{array}$} & 0,42 \\
\hline \multicolumn{4}{|c|}{ Tasa de crecimiento esperable del producto agrario: } & 1,02 \\
\hline \multicolumn{4}{|c|}{ Tasa de crecimiento del producto 1800 - 1882/90: } & 0,78 \\
\hline \multicolumn{4}{|c|}{ Tasa de crecimiento del producto 1800 - 1903/06: } & 0,80 \\
\hline \multicolumn{4}{|c|}{ Tasa de crecimiento del producto $1802 / 06$ - 1882/90: } & 1,10 \\
\hline \multicolumn{4}{|c|}{ Tasa de crecimiento del producto 1802/06 - 1903/06: } & 1,07 \\
\hline
\end{tabular}

Fuentes: Estimado a partir de Lana (1999: 91-151)

el caso de la fuerza de trabajo se ha tomado como indicador el tamaño de la población en 1797 y 1900, ya que determinar la cuantía de los activos agrarios masculinos y femeninos presenta dificultades insalvables y la comarca se mantuvo como un espacio poco industrializado. Por último, se ha estimado la cantidad total de semilla de trigo teniendo en cuenta los rendimientos medios por simiente en cada fecha. Se ha considerado un rendimiento tipo de 1:5 para 1800 , y en consecuencia una reserva de simiente de cada cinco, uno. Sobre la cosecha de 1800 ello representaría 21,5 miles de hectolitros (para la cosecha media de 1802-06 el dato sería de 21,6 si suponemos, teniendo en cuenta las malas cosechas de esos años, un rendimiento de 1:3,5). Para final de siglo se han manejado los rendimientos

\footnotetext{
(F'note continued)

la que arroja el catastro provincial y se ha tomado de Jaén (1904: 28-30). Los coeficientes de producción de estiércol por cabeza de ganado son: 10 tm/año en caballar y mular, 10,5 tm en vacuno, 6 en asnal, 0,55 en ovino o caprino y 1,5 tm en porcino (Memorias provinciales sobre producción y consumo de abonos en el año 1933, Archivo General de la Administración, sección Agricultura, caja $n^{\circ}$ 247). Debo el conocimiento de este informe a la generosidad de Domingo Gallego.
} 
medios proporcionados por las cartillas evaluatorias de 1890 (1:7,7 en regadío y 1:5,35 en secano) y de 1905 (1:10,9 en regadío y 1:5,9 en secano) que permiten calcular un monto de semilla de trigo de 16,9 miles de hectolitros para $1882-90$ y de 25,9 miles de hectolitros en 1903-06. Se ha atribuido a 1900 el promedio de ambas cifras (21,4 miles hls), de modo que resulta un inesperado ahorro en este factor ${ }^{23}$.

Si asumimos los órdenes de ponderación para los factores que figuran en el cuadro 4, la tasa media de incremento de la cantidad de factores de producción asciende a un 0,60 por cien anual. Si a esta cifra añadimos el 0,42 por cien que creció la TFP entre 1790 y 1900 encontramos que el aumento del producto que debió haberse registrado se sitúa en el 1,02 por cien. Las tasas de crecimiento del producto agrícola que podemos estimar a partir de los datos del cuadro 1 se mueven entre 0,78 y 1,10 por cien. Resulta así validado a través de este test el resultado obtenido por la vía de los precios. El ejercicio confirma además el comportamiento observado en los precios de cada uno de los factores. El mayor encarecimiento relativo de los fertilizantes cuadra perfectamente con el hecho de que la cantidad de estiércol disponible por hectárea de cultivo hubiese disminuido en un - 0,83 por ciento anual. El que la tracción animal disponible por hectárea hubiese disminuido en un $-0,33$ por cien por año conforma también con que el jornal de las yuntas se hubiese encarecido relativamente más que la mano de obra. Por último, que los precios del trigo -al mismo tiempo simiente y alimento hubiesen aumentado en una menor proporción a pesar de las tensiones provocadas por el crecimiento demográfico y la extensión de la superficie sembrada es coherente con el ahorro de semilla empleada por unidad de superficie labrada que permite estimar el cuadro 6, nada menos que un -1,1 por cien anual.

\section{3. ¿QUÉ NOS DICEN LOS INDICADORES DIRECTOS DE PRODUCTIVIDAD?}

El resultado obtenido deja como poso algunos interrogantes: ¿Resulta creíble esta distribución temporal del crecimiento de la productividad total de los factores? ¿No estaremos padeciendo una ilusión óptica a causa de la naturaleza de los mercados en que tenía lugar la formación de los precios de mercancías y factores? En concreto, el sólido avance del indicador entre 1817 y 1844, ¿̇no vendrá sesgado por el hecho de que la revolución liberal que acontece entre esas fechas transforma sustancialmente unos mercados que hasta entonces no eran plenamente competitivos? Y de creer lo que sugiere el

${ }^{23}$ Estos rendimientos se han aplicado a la inversa, a fin de estimar la semilla, sobre la cifra de producción de 81.424 hls de trigo en regadío y 33.778 de secano en la comarca de Tudela en la década de 1880 (JCA, 1891a) y de 114.516 hls y 90.642 hls, respectivamente, en 1903-06 (Lana, 1999: 150-151). 


\section{GRÁFICO 3}

INDICADORES PARCIALES DE PRODUCTIVIDAD EN ALGUNAS EXPLOTACIONES AGRÍCOLAS DEL SUR DE NAVARRA, 1790-1900

(medias móviles de 11 años, Base $100=1856$ )

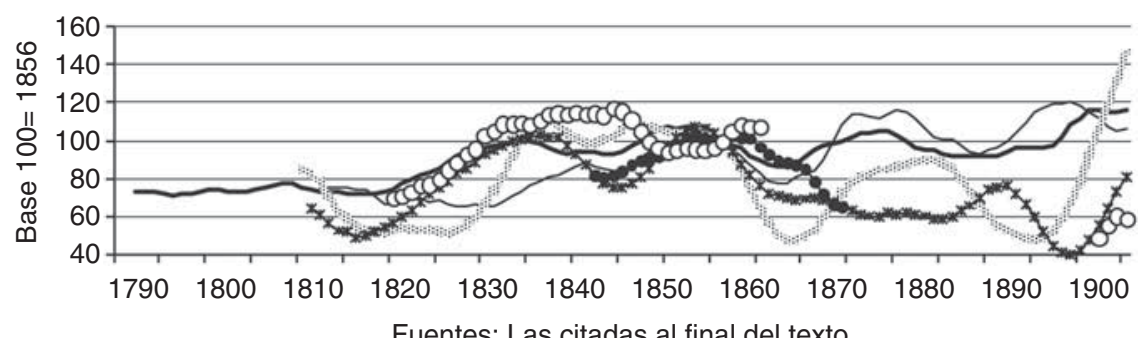

Fuentes: Las citadas al final del texto

\begin{tabular}{l}
$\longrightarrow$ TFP \\
$\longrightarrow$ Cebada (rendimiento de semilla) \\
$\longrightarrow$ Trigo (rendimiento de semilla) \\
$\longrightarrow$ Viñedos del Marqués de San Adrián (productividad del trabajo) \\
$\longrightarrow$ Olivares del Marqués de San Adrián (productividad del trabajo) \\
\hline Olivares del Conde de Murillo (productividad del trabajo)
\end{tabular}

indicador, ¿Qué fuerzas hicieron crecer la productividad total de los factores? ¿Por qué la curva presenta en las décadas centrales del siglo un carácter cíclico tan marcado? ¿Qué es lo que impidió durante la segunda mitad del siglo un avance más decidido de este indicador?

Algunas claves se encuentran en el gráfico 3, que recoge algunos indicadores directos de productividad reconstruidos a partir de la documentación contable. Inevitablemente son indicadores parciales y limitados, que aquí se expresan como números índices en media móvil de once años con la base cien en 1856, de modo que su recorrido pueda ser comparado con el de la TFP. Abarca dos conjuntos de series: en primer lugar, se ofrecen los rendimientos de cosecha por unidad de semilla en el caso de la cebada y, con un número menor de observaciones, el del trigo ${ }^{24}$; en segundo lugar, se presentan tres series con la productividad física del trabajo en algunos viñedos y olivares de Monteagudo y Cintruénigo, obtenida del cociente entre cosecha y peonadas contratadas ${ }^{25}$. Aunque existen diferencias importantes

24 Son 142 observaciones en el caso de la cebada y 65 en el del trigo. Proceden en su mayor parte de fincas de los marqueses de San Adrián en Monteagudo, Tudela y Tulebras, y unas pocas de las del conde de Zaldívar en Cortes. Los datos deben ser tomados con cautela ya que el desplazamiento de las siembras de los propietarios desde el regadío a los campos de secano, o a la inversa, podría introducir graves sesgos.

25 El tratamiento metodológico es similar al desarrollado en Lana (1995). 
en todas estas curvas, se detectan también puntos en común que refuerzan la credibilidad de la serie. Durante la primera mitad del siglo XIX se percibe un doble movimiento de descenso de los indicadores en las dos primeras décadas y de fuerte impulso alcista en los veinte años siguientes. Durante la segunda mitad del siglo se marca también con nitidez una sucesión de ciclos con diferente intensidad. Cabe destacar especialmente el hecho de que los desfallecimientos cíclicos de la curva de la productividad total de los factores que se perciben en torno a 1835-1845, 1854-1864 y 1874-1884 son también identificables en los rendimientos por semilla de los cereales y en la productividad del trabajo en los viñedos y, en menor medida, en los olivares. Pero tal vez lo más relevante de este cotejo es que permite confirmar el fuerte impulso de la productividad que tuvo lugar entre 1817 y 1850, así como los mediocres resultados de la segunda mitad del siglo. ${ }^{26}$

Pero, de nuevo, ¿Cómo explicar estos resultados? Comencemos por recordar una obviedad. Los altos precios de venta del producto estimulan la inversión y el consumo, mientras que la deflación induce a recortar gastos y ahorrar. Esto se puede traducir en un empleo más generoso de factores en el primer caso, mientras que en el segundo caso se impone la necesidad de ajustar un uso eficiente de esos factores. Para las explotaciones que operan con mano de obra asalariada el factor clave en este sentido es la fuerza de trabajo. En años de buenos precios tenderían a contratar más trabajadores mientras que en condiciones de precios a la baja buscarían reducir jornales. Para las explotaciones familiares, sin embargo, el factor que ocuparía esa posición estratégica sería el capital. Los buenos años permitirían acceder a crédito y ampliar el uso de bienes de capital, mientras que los precios bajos obligarían a ajustar ese empleo. El factor tierra jugaría para estas explotaciones una función diferente y ajena a los ciclos, ya que tanto en condiciones de precios altos como de precios bajos la disponibilidad de una mayor cantidad de tierra mejoraría la eficiencia en el uso de la fuerza de trabajo familiar, al elevar la ratio trabajo/tierra. Para las grandes explotaciones, sin embargo, el factor tierra tendría un componente pro-cíclico, de modo que la inflación estimularía la ampliación de la superficie labrada, y consecuentemente la contratación de mano de obra, mientras que la deflación induciría a su abandono, bien mediante su conversión a pastizales, bien mediante su cesión a renta. En suma, el uso de los factores en las explotaciones con mano de obra asalariada sería siempre pro-cíclico, con el trabajo como clave de bóveda, mientras que en las explotaciones familiares tan sólo el uso del capital sería pro-cíclico, tendiendo a ser el de tierra y trabajo más bien anti-cíclico. Sobre este esquema básico hay que superponer el marco

${ }^{26}$ Los coeficientes de correlación entre estas series y la TFP tienen signo positivo, aunque varía mucho desde el 0,668 de los rendimientos de la cebada y el 0,585 de la productividad del trabajo en el viñedo hasta el 0,498 en los olivares del conde de Murillo y el 0,284 en los del marqués de San Adrián. 
institucional y sus transformaciones a lo largo de este periodo. $\mathrm{Y}$ en esto el quid radica, como es sabido, en el factor tierra. Las constricciones que el sistema feudal establecía sobre la utilización y movilidad de este factor no son probablemente ajenas al estancamiento de la productividad que muestra la curva TFP, como tampoco lo será la ruptura de ese marco institucional para el crecimiento posterior ${ }^{27}$.

La deflación que siguió a las guerras napoleónicas afectó de modo diverso a grandes y pequeñas explotaciones. Las primeras se vieron estimuladas a economizar jornales en sus plantaciones o bien a traspasar el coste del ajuste a la agricultura familiar mediante arrendamientos y censos reservativos y enfitéuticos. Las segundas se vieron forzadas a ahorrar capital y a presionar políticamente para aumentar la superficie labrada con el fin de incrementar la cantidad de producto comercializado o, por el contrario, de garantizarse un refugio viable en el autoconsumo. Así es que las ganancias de productividad que refleja la curva tuvieron lugar mayormente en un contexto de avance de la agricultura familiar y de retroceso de la gran explotación con mano de obra asalariada; un esquema que volvió a repetirse en las dos últimas décadas del siglo.

Pero, ¿cuáles fueron los medios a través de los que se aumentó la productividad entre 1817 y 1850? Algunos se han detectado ya gracias a la documentación contable de grandes explotaciones. Las plantaciones de olivares, y más tarde también los viñedos, se hicieron más eficientes en el uso del factor trabajo. Y también en el de la tierra. ${ }^{28}$ Esto no sucedió de repente, sino que fue el resultado de mejoras introducidas desde finales del siglo XVIII. Un marco de plantación más denso y nuevas variedades, como el empeltre (un olivo que requería ser injertado), explican el aumento de la producción por hectárea. Si esto no se tradujo en el uso de más fuerza de trabajo fue por la introducción de algunas prácticas de cultivo (nuevos sistemas de poda y de cava y entrecava) que permitían ahorrar jornales en las tareas más voluminosas. La respuesta de las pequeñas explotaciones es documentalmente más incierta, pero conocemos con seguridad tres hechos: el primero, la ampliación de la superficie regada, gracias a algunas obras modestas y al aprovechamiento de aguas sobradas; el segundo, la difusión de nuevos cultivos en las rotaciones del regadío, como la patata, el maíz y, más tarde, la alfalfa; el tercero, la puesta en cultivo de tierras vírgenes que proporcionaron elevados rendimientos durante unos años. ${ }^{29}$

27 Algo que ya destacó Moreau de Jonnes (1835: 144-145); Llopis (1983); García Sanz (1985).

28 El rendimiento por hectárea de los olivares del conde de Murillo aumentó un 61 por cien entre 1810-19 y 1830-39; el de los del marqués de San Adrián lo hicieron en un 97 por cien entre 1801-11 y 1843-1847; el de los viñedos de este último creció en un 47 por cien entre 1798-1802 y 1843-47.

29 En las cuentas de Tulebras de 1845 el administrador del marqués de San Adrián advertía que el extraordinario producto de la siembra de trigo (con un rendimiento de 1:21) "no se deberá traer en consecuencia" por dos circunstancias: "ser el terreno tierra noval o virgen" y "las propicias lluvias" de esa primavera (AMSA, cj.11). 
El avance de los rendimientos en el cereal pudo también proceder de cambios poco perceptibles y poco costosos en las prácticas de cultivo, como un laboreo más cuidadoso, el tratamiento de la semilla con soluciones alcalinas para prevenir enfermedades, la siembra a mayor profundidad o un marco de siembra menos denso ${ }^{30}$. Esto último pudo tener particular importancia. Páginas atrás se ha señalado la paradoja de que, según nuestra estimación, la cantidad de semilla empleada en la comarca se redujo a pesar de la ampliación de la superficie sembrada. Precisamente los tratados de agronomía, sobre todo desde 1830, insistieron en la posibilidad y conveniencia de ahorrar semilla, sintetizándolo en una fórmula proverbial que facilitaba su difusión: "Quien siembra claro, recoge espeso" ${ }^{\prime 31}$. La respuesta en rendimiento de grano a variaciones de densidad de siembra ha sido, en efecto, descrita como una curva parabólica, dado que a partir de un cierto umbral se impide macollar adecuadamente a la planta, reduciendo el número de tallos y de espigas obtenidas por metro cuadrado. ${ }^{32}$ Esto ofrecía un amplio margen de mejora tan sólo con aproximarse al óptimo de la curva en la densidad de siembra, con la ventaja añadida de permitir aminorar los riesgos y de ahorrar el medio de producción más escaso en la agricultura del siglo XIX: el capital circulante. Tampoco podemos desechar la posibilidad de que se difundieran semillas de mayor rendimiento, a pesar de que los indicios apuntan a una estabilidad en el mapa de variedades de trigo entre 1818 y 1877 . La extendida creencia en que las semillas degeneraban y en que era conveniente su sustitución periódica por granos traídos de otras localidades más o menos alejadas ofrecía una oportunidad para su sustitución ${ }^{33}$.

La década de 1850 supone un punto de ruptura en la evolución de la productividad. El contexto sociológico había para entonces cambiado. Los hacendados, con las nuevas oportunidades abiertas en España por la desamortización, la creciente urbanización y la inversión en ferrocarriles y banca, habían recobrado la iniciativa perdida en los años veinte, apostando de nuevo

30 Desde fines del siglo XVIII algunos de estos procedimientos eran predicados en Navarra por clérigos y propietarios ilustrados (Larumbe, 1800: 65) (Sorauren, 1986).

31 Forgas (1996: 127). En 1836 la Sociedad Económica Matritense convocó un certamen sobre el tema de la cantidad óptima de semilla por unidad de superficie. El premio lo obtuvo Concepción de Arias (hija del agrónomo Antonio Sandalio de Arias) con un informe que recomendaba reducir la cantidad de semilla por unidad de superficie en un 55\% (Antón Ramírez, 1865: 282). A mediados de siglo la recomendación se repite en obras como las de Casas (1845: 75), Olivan (1849: 54-55), Ramírez Arcas (1855: 192), Arias (1856: 92-93), López Martínez (1856: 224) y Blanco Fernández (1857:197-198). El aclarado del marco de siembra parece confirmarse en algunas investigaciones locales (Garrabou, Pascual, Pujol \& Saguer, 1995: 109). Todavía en 1880 Abela estimaba la cantidad de semilla que podía ser economizada en España en nueve millones de hectolitros de trigo (Abela, 1880: 290).

32 Holliday (1960); Scott et al. (1973); Hutchings y Budd (1981).

33 López Martínez (1856: 222). Además, muchos hacendados acostumbraban a prestar la simiente a sus colonos, no por filantropía sino por asegurar la calidad del trigo que cobraban de rentas, con lo cual expandían socialmente esa oportunidad para la mejora genética. El mapa de las variedades de trigo, en Barquín (2001:26). Olmstead \& Rhode (2008: 17-63) destacan el protagonismo de las semillas en el crecimiento agrario decimonónico. 
por el cultivo directo y la transformación industrial de materias primas agrícolas como la uva y la aceituna en bodegas y almazaras renovadas con destino a los mercados nacional y exterior. ${ }^{34}$ Un cultivo más esmerado y unas inversiones más ambiciosas - auspiciadas por la expansión y mejora del mercado de crédito $^{35}$ - no parecían ser una elección errónea, al menos hasta que pudo cobrarse conciencia a finales del siglo de la creciente competencia internacional. Lo cierto es que ese esfuerzo no se tradujo en una mejora sustancial y sostenida de la eficiencia productiva. En parte ello se debió a factores exógenos. Las décadas de 1850 y 1880 fueron testigos de una sucesión calamitosa de fenómenos atmosféricos y de epidemias letales sobre las cosechas (oidio y mildew en la vid, y negrilla -Capnodium elaeophilum- en el olivo) y sobre la fuerza de trabajo (el cólera morbo). ${ }^{36}$ Pero ello no puede ocultar que parecía haberse alcanzado un techo tecnológico y organizativo del que los mejores exponentes son, en primer lugar, la recurrencia de los ciclos que podemos asociar a los rendimientos decrecientes de las tierras roturadas en sucesivas oleadas, y en segundo lugar, el fortísimo ascenso del precio de los fertilizantes (2,12 por cien anual en 1844-63) y de las yuntas (1,19 por cien en 1882-1900) (cuadro 5). Esto último demuestra hasta que punto los mercados de bienes de capital se encontraban sometidos a presión durante esos años y lo comprometido que se hallaba el mantenimiento de los niveles de productividad del suelo. La oferta industrial de fertilizantes químicos terminaría por romper ese bloqueo desde la última década del siglo ${ }^{37}$, pero para entonces el escenario social había vuelto a cambiar. Muchos hacendados habían renunciado al cultivo directo y habían apostado de nuevo por una estrategia rentista, confiados en que los costes de producción recaerían sobre la familia del arrendatario y en que las ventajas de los precios garantizados por el arancel proteccionista continuarían favoreciéndole.

\section{CONCLUSIONES}

En este texto se ha ensayado una metodología poco utilizada hasta el momento en la historia agraria española y no exenta de críticas desde diversas posiciones. Se ha apostado por aprovechar la solidez de las series de precios construidas a partir de fuentes contables de cobertura regional para ensayar una aproximación a la evolución de la productividad total de los factores durante el siglo XIX. El balance resulta satisfactorio. La curva de TFP resultante parece coherente con lo que apuntan otras informaciones e indicadores que no toman los precios como base, de modo que la metodología escogida parece adecuada dadas las circunstancias en que se ha aplicado.

\footnotetext{
34 Garrabou, Planas y Saguer (2001); Robledo y López (2007).

35 La oferta de crédito en el sur de Navarra se multiplicó por algo más de dos en la década de 1850 respecto a la anterior (De la Torre \& Lana, 2011). Vid. Tello (2007) y Pérez Picazo (2005).

36 JCA (1891b); JCA (1891b); Pan-Montojo (1994); Martínez Lacabe (2004).

37 Garrabou y González de Molina (2010); Pujol (1998).
} 
Los resultados fortalecen además la idea de que el sector agrario creció durante el siglo XIX y de que una parte muy destacada de ese crecimiento tuvo lugar durante el oscuro periodo que siguió al fin de las guerras napoleónicas. La novedad reside en que ese crecimiento, además de venir acarreado por una ampliación extensiva de los factores de producción (en especial de la tierra), responsables de tres quintas partes del aumento del producto, se debió también en parte a una mejora de la eficiencia en el uso de los factores, que aportó los dos quintos restantes. Como resortes concretos que permitieron esa vía intensiva se pueden citar la expansión y cambios de prácticas en los cultivos leñosos, cuya productividad laboral se elevó después de 1815, una consolidación y modesta ampliación del regadío, incluyendo la difusión de nuevas plantas (patata, maíz, alfalfa), y el ahorro de semilla en el cultivo de cereales, que redujo riesgos y mejoró el uso del capital circulante. Ese crecimiento, con todo, no tuvo lugar a través de una secuencia sostenida, sino que padeció repetidos desfallecimientos con periodos de recuperación y aceleración de diferente intensidad. Tan destacable como la solidez del avance en la productividad entre 1790 y 1900 (0,42 por cien anual) resulta la naturaleza fuertemente cíclica del mismo a mediados del siglo XIX y el techo que pareció alcanzarse en ese momento. El comportamiento de los precios de los distintos insumos permite atribuir a la oferta de fertilizantes y de tracción animal un papel muy destacado en los mediocres resultados que muestra la curva durante la segunda mitad del siglo XIX.

Ha de quedar necesariamente como incógnita hasta qué punto el resultado obtenido en este ejercicio es extrapolable a otras zonas de la Península. La comarca presenta algunos rasgos (baja densidad de población relativa, moderadas pendientes, hidrografía favorable, vías de comunicación) que hacían factible un proceso de especialización y colonización interior que no se daban en otras partes del país. En cualquier caso, determinar la representatividad del caso analizado debería servir de estímulo para profundizar y extender el análisis a otras regiones en las que el mercado como mecanismo de asignación de recursos tuviese igualmente presencia.

\section{FUENTES:}

Archivo de los Marqueses de San Adrián (A.MSA), Monteagudo (Navarra) [Depositado en el Archivo Municipal de Tudela entre 1990 y 2008, donde tuve ocasión de consultarlo]

Cuentas generales: cajas $11 ; 14 ; 15 ; 17 ; 18 ; 19 ; 24 ; 25 ; 29 ; 30 ; 33 ; 34 ; 38 ; 41$; $43 ; 44 ; 49 ; 50 ; 53 ; 55 ; 58 ; 62 ; 64$.

Archivo de los Duques de Miranda (A.DM), Traibuenas (Navarra)

Cuentas anuales, 1862-67, 1868-73, 1874-81, 1884-87, 1891-93, 1900-06.

Libro de Frutos, 1859-89.

Archivo Histórico Nacional, Sección Nobleza (SNAHN), Toledo 
Bornos, cajas 172(1), 173(1), 203(16), 234(4), 471(8), 485(19), 630(2), 670(1). Archivo General de Navarra (AGN), Pamplona

Sección Clero. Fitero (Libro $n^{\circ} 458$ ); La Oliva (Libro $n^{\circ}$ 533); Tulebras (Libro $n^{\circ} 324$ ).

Sección Archivos particulares. Arteta: cajas 12 (14), $13(53), 14(21,33)$ y 15 (2, 27), 16 (49). Baronía de La Torre: cajas 1, 12, 19, 24 y 26.

Sección Protocolos notariales. Cuentas del estado de Sartaguda. Notaría de Lodosa, José Manuel Pinillos, legajos 278(206), 279(143), 281(7), 282(66), 284(115), 284(72), 285(74), 285(34), 285(41), 285(54), 286(47), 287(62), 287(28), 295(187), 296(159), 296(126), 297(160); años 1849 (folios 46-91), 1850 (ff.5-57), 1850 (ff.483-558), 1851 (ff.319-379), 1852 (ff.313-359), 1854 (ff.6-51), 1856 (ff.19-112).

Sección Diputación Foral de Navarra. Administración Municipal: Cuentas municipales de Carcastillo (cajas.14237-14241), Tudela (cj. 19350-19486), Villafranca (cj.19963-19994), Monteagudo (cj.17907-17911), Arguedas (cj. 13394-13426), Mélida (cj.17674-17684), Cortes de Navarra (cj. 14562-14574), San Adrián (cj. 18875-18897).

Sección Archivos Municipales. Villafranca, Libros de cuentas de la Villa, cajas $34878,34879,34880$.

Archivo de la Casa de Misericordia de Pamplona (ACMP), Pamplona

Cuentas de la casa de Misericordia, cajas 43, 59, 81, 82, 86, 270-272

Archivo Municipal de Pamplona (AMP), Pamplona

Casa de Misericordia, legajos.22-76.

Carnicerías, legajos. 8-15, 80-114.

Archivo Municipal de Tudela (AMT), Tudela

Hospital de Nuestra Señora de Gracia, Libros de cuentas generales, CG3, libros n¹62 y 163 .

Abastos, Carnicerías, cajas. 5, 6, 7, 8, 9, 10, 11, 13.

Archivo Diocesano de Tudela (ADT), Tudela.

Parroquia Santa María Magdalena, Libro de cuentas nº 6 (1778-1821)

\section{BIBLIOGRAFÍA}

Abela Sáinz de Andino, E. (1880): «Reformas convenientes en el sistema de explotación de cereales», en Conferencias agrícolas de la provincia de Madrid. Madrid, IV, pp. 271-325.

AlLEN, R. C. (1992): Enclosures and the Yeoman: The agricultural development of the South Midlands, 1450-1850. Oxford: Clarendon Press.

Allen, R. C. (2004): Revolución en los campos. La reinterpretación de la revolución agrícola inglesa. Zaragoza: Prensas Universitarias de Zaragoza.

Antón Ramírez, B. (1865): Diccionario de bibliografía agronómica. Madrid.

Arias Costa, A. S. (1856): Novísima Agricultura práctica. Madrid. 
Barquín, R. (2001): Precios de trigo e índices de consumo en España. 17651883. Burgos: Universidad de Burgos.

Bernal, A. M. (1999): "La agricultura y ganadería españolas en el siglo XIX», en G. Anes (Ed.), Historia económica de España, siglos XIX y XX. Madrid: Galaxia Gutenberg, pp. 83-183.

Blanco Fernández, A. (1857): Elementos de agricultura. Madrid.

BRINGAS, M. A. (2000): La productividad de los factores en la agricultura española (1752-1935). Madrid: Banco de España.

Burkett, P. (2006): «Total Factor Productivity. An Ecological-Economic Critique». Organization \& Environment 19 (2), pp. 171-190.

Calatayud, S. y Martínez Carrión, J. M. (1999): «El cambio técnico en los sistemas de captación e impulsión de las aguas subterráneas para riego en la España mediterránea», en R. Garrabou y J. M. Naredo (eds.), El agua en los sistemas agrarios. Una perspectiva histórica. Madrid: Argentaria/Visor, pp. 15-39.

Carmona Pidal, J. y Simpson, J. (2003): El laberinto de la agricultura española. Instituciones, contratos y organización entre 1850 y1936. Zaragoza: Prensas Universitarias de Zaragoza.

Casas, N. (1845), Tratado de agricultura española teórico-práctica. Parte sexta. Madrid.

CLARK, G. (1993): «Agriculture and the Industrial Revolution: 1700-1850», en J. Mokyr (ed.), The British Industrial Revolution. An economic perspective. Boulder-San Francisco-Oxford: Westview Press, pp. 227-266.

Clark, G. (1999): "Too Much Revolution: Agriculture in the Industrial Revolution, 1700-1860», en J. Mokyr (ed.), British Industrial Revolution: An economic perspective. Boulder: Westview Press, pp. 206-240.

Coll, S. y Bringas, M. A. (2000): «Estimating Single Input Productivity, Total Factor Productivity and Output from price data. An application to Spanish agriculture, 1800-1935». Histoire \& Mesure 15, pp. 339-353.

CRAFTS, N. F. R. (1985): British Economic Growth during the Industrial Revolution. New York: Oxford University Press.

De La Torre, J. y Lana, J. M. (2011): «Land market and credit in the transition to Capitalism. Navarra, $18^{\text {th }}-19^{\text {th }}$ centuries», en G. Béaur y P. R. Schofield (eds.), Property Rights, Land in Market and Economic Growth. Turnhout: Brepols, pp. 1-19.

De la Torre, J., Ed. (1994): Navarra, Siglo XIX, 1800-1900: Cien años de historia. Pamplona: Instituto Gerónimo de Uztáriz.

Domínguez, R. (2002): La riqueza de las regiones. Las desigualdades económicas regionales en España, 1700-2000. Madrid: Alianza.

FEDERICO, G. (2005): Feeding the World. An economic history of agriculture. Princeton: Princeton University Press.

FonsecA, H. A. y ReIs, J. (2011): «The limits of agricultural growth in a fragile eco-system. Total Factor Productivity in Alentejo, 1750-1850», en M. Olsson y P. Svensson (eds.), Growth and stagnation in European historical agriculture. Turnhout: Brepols (en prensa). 
Forgas, E. (1996): Los ciclos del pan y del vino en las paremias hispanas. Madrid: Ministerio de Agricultura.

G.E.H.R. (Grupo de Estudios de Historia RuRAL) (1983): "Notas sobre la producción agraria española, 1891-1931». Revista de Historia Económica 1 (2), pp. 185-252.

G.E.H.R. (GRUPO DE Estudios DE Historia RURAL) (1991): Estadísticas históricas de la producción agraria española, 1859-1935. Madrid: Ministerio de Agricultura.

GALlEGO, D. (2001): «Sociedad, naturaleza y mercado: un análisis regional de los condicionantes de la producción agraria española (1880-1936)». Historia Agraria 24, pp. 11-57.

Gallego, D. y Pinilla, V. (1996): «Del librecambio matizado al proteccionismo selectivo: el comercio exterior de productos agrarios en España entre 1849 y 1935». Revista de Historia Económica 14, pp. 371-420, y pp. 619-640.

Gallman, R. E. (1972): "Changes in Total U.S. Agricultural Factor Productivity in the Nineteenth Century». Agricultural History 46 (1), pp. 191-210.

GARCía SANZ, A. (1985): “Crisis de la agricultura tradicional y revolución liberal (1800-1850)», en A. García Sanz y R. Garrabou (eds.), Historia agraria de la España contemporánea. 1. Cambio social y nuevas formas de propiedad (1800-1850). Barcelona: Crítica, pp. 7-99.

GARRABOU, R. (1990): «Sobre el atraso de la mecanización agraria en España (1850-1933)». Agricultura y Sociedad 57, pp. 41-77.

Garrabou, R. y González de Molina, M. (eds.) (2010): La reposición de la fertilidad en los sistemas agrarios tradicionales. Barcelona: Icaria.

GarRabou, R. y SANZ Fernández, J. (1985): «La agricultura española durante el siglo XIX: ¿inmovilismo o cambio?», en R. Garrabou y J. Sanz (eds.), Historia agraria de la España contemporánea. 2. Expansión y crisis (18501900). Barcelona: Crítica, pp. 7-191.

Garrabou, R.; Pascual, P.; Pujol, J. y Saguer, E. (1995): «Potencialidad productiva y rendimientos cerealícolas en la agricultura catalana contemporánea (1820-1935)». Historia Agraria 10, pp. 89-130.

Garrabou, R.; Planas, J. y Saguer, E. (2001): Un capitalisme impossible? La gestió de la gran propietat agrària a la Catalunya contemporània. Vic: Eumo.

Grantham, G. (1996): «The French agricultural capital stock, 1789-1914». Research in Economic History 16, pp. 39-83.

Grantham, G. (2000): "The French Agricultural Productivity Paradox: Measuring the Unmeasurable». Historical Methods 33, pp. 36-46.

HofFman, P. T. (1991): «Un nouvel indice de la productivité agricole: les baux de Nôtre-Dame de Paris, 1450-1789». Histoire et Mesure 6, pp. 215-243.

Hoffman, P. T. (1996): Growth in a Traditional Society. The French countryside, 1450-1815. Princeton: Princeton University Press. 
Holliday, R. (1960): «Plant population and crop yield: part I». Field Crop Abstracts 13 (3), pp. 159-167.

Hutchings, M. J. y Budd, C. S. J. (1981): «Plant competition and its course through time». BioScience 31, pp. 640-645.

JAÉN, C (1904): Memoria sobre la tierra labrantía y el trabajo agrícola en la provincia de Navarra. Madrid.

JCA (Junta Consultiva Agronómica) (1891a): Avance estadístico sobre el cultivo cereal y de leguminosas asociadas en España. Madrid, 2 vols.

JCA (Junta Consultiva Agronómica) (1891b): Avance estadístico sobre cultivo y producción de la vid en España. Madrid.

JCA (Junta Consultiva Agronómica) (1891c): Avance estadístico sobre cultivo y producción del olivo en España. Madrid.

Jorgenson, D. y Grilliches, Z. (1967): «The Explanation of Productivity Change». Review of Economic Studies 57, pp. 638-655.

KNIBBE, M. (2006): Lokkich Fryslân. Landpacht, arbeidsloon en landbouwproductiviteit in het Friese kleigebied, 1505-1830. Groningen/Wageningen: Nederlands Agronomisch Historisch Intituut.

Kondo, A. Y. (1990): La agricultura española del siglo XIX. Madrid: Nerea.

LANA, J. M. (1995): «Trabajo, técnica y mercado en la viticultura navarra: los viñedos del Marqués de San Adrián en Monteagudo durante el siglo XIX». Historia Agraria 10, pp. 135-163.

LANA, J. M. (1999): El sector agrario navarro (1785-1935): Cultivo, ganadería, propiedad y mercados. Pamplona: Gobierno de Navarra.

Larumbe, J. M. (1800): Epítome cristiano de Agricultura, según las instrucciones del Semanario, y de las puras fuentes de donde se derivan. Pamplona.

Le Goff, T. J. A. y Sutherland, D. M. G. (2000): «What can we learn from leases? A preliminary view». Histoire \& Mesure 15, pp. 289-320.

LLopis, E. (1983): «Algunas consideraciones acerca de la producción agraria castellana en los veinticinco últimos años del Antiguo Régimen». Investigaciones económicas 21, pp. 135-151.

Llopis, E. (ed.) (2004): El legado económico del Antiguo Régimen en España. Barcelona: Crítica.

López Martínez, M. (1856): Elementos de agronomía, agricultura y economía rural. Madrid.

Martínez CARrión, J. M. (ed.) (2002): El nivel de vida en la España rural, siglos XVIII-XX. Alicante: Universidad de Alicante.

Martínez Lacabe, E. (2004): Violencia y muerte en Navarra. Guerras, epidemias $y$ escasez de subsistencias en el siglo XIX. Pamplona: Universidad Pública de Navarra.

McCloskey, D. (1975): «The Economics of Enclosure: A market Analysis», en W. N. Parker \& E. L. Jones (eds.), European Peasants and their markets. Princeton: Princeton University Press, pp. 132-133.

Moreau de Jonnes, A. (1835): Estadística de España, traducida y adicionada por Pascual Madoz e Ibáñez. Barcelona. 
Olivan, A. (1849): Manual de agricultura. Madrid.

Olmstead, A. L. y Rhode, P. W. (2008): Creating Abundance. Biological innovation and American agricultural development. New York: Cambridge University Press.

Overton, M. y CAmpBell, B. M. S. (1999): «Statistics of production and productivity in English agriculture, 1086-1871», en J. P. Van Bavel y E. Thoen (eds.), Land productivity and agro-systems in the North Sea area, Middle Ages-20th century. Elements for comparison. Turnhout: Brepols, pp. 189-208.

Pan-Montojo, J. (1994): La bodega del mundo. La vid y el vino en España (1800-1936). Madrid: Alianza.

PÉrez Picazo, M. T. (2005): «El mercado de factores en la agricultura murciana durante el siglo XIX». Investigaciones de Historia Económica 2, pp. 39-74.

Pérez Picazo, M. T. (2006): «Los progresos de la historiografía agrarista sobre el siglo XIX. Crecimiento, cambio institucional y problemas medioambientales», en C. Barciela, G. Chastagnaret y A. Escudero (eds.), La Historia Económica en España y Francia. Siglos XIX y XX. Alicante: Universidad de Alicante \& Casa de Velázquez, pp. 69-135.

Persson, K. G. (2010): An Economic History of Europe. Knowledge, Institutions and Growth, 600 to the Present. Cambridge: Cambridge University Press.

Pujol, J. (1998): "La difusión de los abonos minerales y químicos hasta 1936: el caso español en el contexto europeo». Historia Agraria 15, pp. 143-184.

Pujol, J.; González-de-Molina, M.; Fernández Prieto, L.; Gallego, D. y Garrabou, R. (2001): El pozo de todos los males. Sobre el atraso en la agricultura española contemporánea. Barcelona: Crítica.

Ramírez ARCAS, A. (1855): Tratados de estadística general y nociones preliminares de su formación. Madrid. 2 vols.

Robledo, R. (ed.) (2010): Sombras del progreso. Las huellas de la historia agraria. Barcelona: Crítica.

Robledo, R. y López, S. (coords.) (2007): ¿Interés particular, bienestar público?: grandes patrimonios y reformas agrarias. Zaragoza: Universidad de Zaragoza.

SANZ BAEZA, F. (1858): Estadística de la provincia de Navarra. Pamplona.

Scott, W. R.; Dougherty, C. T.; Langer, R. H. M. y Meijer, G. (1973): "Wheat yield as affected by sowing rate, irrigation, and time of White clover introduction». New Zealand Journal of Experimental Agriculture 1, pp. 369-376.

SimPSON, J. (1997): La agricultura española (1765-1965): la larga siesta. Madrid: Alianza.

SORAUREN, M. (1986): «Algunos aspectos de la agricultura navarra en el tránsito del antiguo al nuevo régimen». Príncipe de Viana, anejo IV, pp. 315-329. 
Sutherland, D. (2003): «Production et croissance: les fermes de l'hôpital du Mans, 1660-1914», comunicación al coloquio Production et productivité agricoles dans le monde occidental (XIVe-XXe siècles) (Paris, diciembre 2003).

SwartZ, R. S. (2000): «Adieu to the Village Immobile in Early Modern France». Historical Methods 33 (1), pp. 31-35.

Tello, E. (2007): «Crisis del antiguo régimen y crisis del sistema crediticio: El fin de los censos consignativos en España (1705-1885)», en S. de Dios, J. Infante, R. Robledo y E. Torijano (eds.), Historia de la propiedad. Crédito y garantía. Madrid: Fundación Registral, pp. 237-269.

Yanguas, Y. y Miranda, J. (1828): Diccionario histórico-político de Tudela. Zaragoza. 
CUADRO A 1

NÚMEROS ÍNDICES DE PRECIOS AGRARIOS, COSTES DE PRODUCCIÓN Y PRODUCTIVIDAD TOTAL DE LOS FACTORES EN LA AGRICULTURA DEL SUR DE NAVARRA, 1782-1900 (1856= BASE 100 Y CAMBIO DE PONDERACIONES)

\begin{tabular}{|c|c|c|c|c|c|c|c|c|}
\hline & TFP & Precios agrarios & Costes de producción & Salario & Renta + diezmo & Alquiler de yunta & Fertilizantes & Semilla de trigo \\
\hline 1780 & & & & & & & & \\
\hline 1781 & & & & & & & & \\
\hline 1782 & 91,01 & 57,16 & 52,02 & 64,44 & 40,06 & 52,43 & 47,58 & 48,94 \\
\hline 1783 & 89,08 & 62,61 & 55,77 & 65,36 & 48,24 & 52,43 & 49,21 & 57,27 \\
\hline 1784 & 88,23 & 64,34 & 56,77 & 64,02 & 53,65 & 52,98 & 44,11 & 60,40 \\
\hline 1785 & 94,02 & 61,53 & 57,85 & 64,59 & 54,56 & 55,22 & 43,70 & 62,32 \\
\hline 1786 & 89,72 & 63,03 & 56,55 & 64,59 & 51,87 & 52,74 & 45,62 & 60,13 \\
\hline 1787 & 94,05 & 61,92 & 58,23 & 71,29 & 47,23 & 63,21 & 36,90 & 57,13 \\
\hline 1788 & 92,23 & 67,27 & 62,04 & 75,05 & 51,13 & 69,08 & 34,46 & 63,88 \\
\hline 1789 & 86,31 & 76,83 & 66,31 & 64,69 & 62,02 & 85,81 & 35,86 & 77,48 \\
\hline 1790 & 87,21 & 71,58 & 62,43 & 64,69 & 52,59 & 87,53 & 34,58 & 63,32 \\
\hline 1791 & 93,64 & 63,24 & 59,22 & 64,02 & 46,46 & 79,47 & 42,01 & 55,94 \\
\hline 1792 & 93,44 & 57,06 & 53,31 & 64,02 & 34,86 & 78,82 & 41,22 & 41,52 \\
\hline 1793 & 83,43 & 101,68 & 84,84 & 85,36 & 97,62 & 79,64 & 42,90 & 114,11 \\
\hline 1794 & 90,68 & 106,57 & 96,63 & 96,37 & 103,31 & 107,89 & 42,90 & 122,06 \\
\hline 1795 & 82,85 & 108,72 & 90,07 & 93,64 & 86,52 & 105,09 & 48,78 & 99,68 \\
\hline
\end{tabular}


CUADRO A 1 (Cont.)

\begin{tabular}{|r|r|r|r|r|r|r|r|r|}
\hline 1796 & 81,92 & 114,25 & 93,59 & 93,47 & 98,50 & 102,29 & 47,14 & 115,83 \\
\hline 1797 & 93,60 & 97,03 & 90,82 & 93,57 & 81,76 & 119,89 & 47,25 & 95,89 \\
\hline 1798 & 100,35 & 87,43 & 87,73 & 87,73 & 78,39 & 113,80 & 54,30 & 94,49 \\
\hline 1799 & 103,03 & 84,45 & 87,01 & 93,78 & 73,08 & 101,92 & 69,65 & 85,97 \\
\hline 1800 & 101,81 & 83,58 & 85,09 & 86,03 & 95,36 & 74,99 & 63,31 & 102,29 \\
\hline 1801 & 92,57 & 93,61 & 86,65 & 85,37 & 97,46 & 78,79 & 63,37 & 106,79 \\
\hline 1802 & 79,08 & 123,33 & 97,53 & 88,36 & 131,01 & 82,61 & 58,94 & 141,03 \\
\hline 1803 & 83,26 & 120,00 & 99,91 & 85,45 & 141,06 & 85,02 & 61,94 & 151,39 \\
\hline 1804 & 94,09 & 105,08 & 98,87 & 82,73 & 129,08 & 98,50 & 63,03 & 136,18 \\
\hline 1805 & 95,45 & 92,04 & 87,86 & 85,02 & 86,24 & 98,14 & 71,32 & 94,75 \\
\hline 1806 & 102,70 & 70,14 & 72,04 & 75,24 & 59,70 & 84,43 & 78,78 & 64,43 \\
\hline 1807 & 98,43 & 84,58 & 83,25 & 91,19 & 69,67 & 92,93 & 81,68 & 74,76 \\
\hline 1808 & 107,42 & 79,49 & 85,39 & 98,53 & 65,75 & 103,20 & 78,06 & 70,00 \\
\hline 1809 & 95,37 & 79,23 & 75,56 & 86,22 & 55,46 & 99,68 & 67,91 & 60,55 \\
\hline 1810 & 79,84 & 120,38 & 96,11 & 83,50 & 109,33 & 108,71 & 63,21 & 120,35 \\
\hline 1811 & 82,51 & 140,43 & 115,87 & 101,51 & 156,55 & 104,66 & 65,44 & 169,96 \\
\hline 1812 & 78,31 & 158,39 & 124,03 & 106,51 & 166,69 & 136,32 & 43,62 & 187,05 \\
\hline 1813 & 83,36 & 121,61 & 101,37 & 112,63 & 94,58 & 137,20 & 32,50 & 105,28 \\
\hline 1814 & 78,52 & 125,92 & 98,88 & 121,87 & 78,50 & 143,07 & 34,95 & 85,56 \\
\hline 1815 & 86,54 & 126,08 & 109,11 & 111,82 & 108,06 & 143,07 & 42,55 & 118,92 \\
\hline
\end{tabular}


CUADRO A 1 (Cont.)

\begin{tabular}{|c|c|c|c|c|c|c|c|c|}
\hline & TFP & Precios agrarios & Costes de producción & Salario & Renta + diezmo & Alquiler de yunta & Fertilizantes & Semilla de trigo \\
\hline 1816 & 93,21 & 120,52 & 112,34 & 104,03 & 114,09 & 136,37 & 81,11 & 119,28 \\
\hline 1817 & 93,64 & 112,41 & 105,26 & 106,51 & 94,23 & 131,67 & 81,40 & 99,47 \\
\hline 1818 & 103,11 & 97,54 & 100,58 & 108,55 & 79,80 & 128,11 & 93,17 & 85,16 \\
\hline 1819 & 116,58 & 68,17 & 79,47 & 93,75 & 56,82 & 103,78 & 76,01 & 59,14 \\
\hline 1820 & 113,37 & 69,84 & 79,18 & 86,87 & 68,75 & 89,12 & 66,30 & 72,08 \\
\hline 1821 & 124,85 & 59,61 & 74,43 & 80,59 & 53,00 & 99,49 & 97,88 & 55,58 \\
\hline 1822 & 114,62 & 71,84 & 82,34 & 81,29 & 77,77 & 95,30 & 72,03 & 79,97 \\
\hline 1823 & 104,80 & 72,49 & 75,97 & 84,20 & 58,74 & 99,49 & 68,77 & 60,16 \\
\hline 1824 & 101,76 & 76,21 & 77,55 & 86,69 & 68,77 & 94,44 & 45,08 & 70,70 \\
\hline 1825 & 111,66 & 71,33 & 79,65 & 84,02 & 67,84 & 102,02 & 62,54 & 69,31 \\
\hline 1826 & 136,23 & 55,78 & 75,99 & 82,53 & 56,70 & 106,28 & 73,91 & 57,75 \\
\hline 1827 & 133,22 & 54,43 & 72,51 & 84,20 & 55,42 & 89,94 & 66,27 & 56,24 \\
\hline 1828 & 123,22 & 57,56 & 70,92 & 81,03 & 56,17 & 86,93 & 61,17 & 57,24 \\
\hline 1829 & 128,38 & 47,13 & 60,50 & 75,35 & 39,37 & 88,31 & 50,15 & 41,36 \\
\hline 1830 & 120,88 & 51,34 & 62,06 & 80,33 & 43,38 & 76,22 & 51,14 & 45,49 \\
\hline 1831 & 121,82 & 54,93 & 66,92 & 77,28 & 53,67 & 81,62 & 50,34 & 56,61 \\
\hline 1832 & 135,37 & 50,94 & 68,96 & 73,71 & 58,33 & 88,34 & 50,22 & 61,74 \\
\hline 1833 & 137,53 & 46,66 & 64,17 & 62,15 & 51,47 & 90,88 & 68,22 & 54,81 \\
\hline 1834 & 115,35 & 56,64 & 65,33 & 66,44 & 56,86 & 82,97 & 52,55 & 60,87 \\
\hline
\end{tabular}


CUADRO A 1 (Cont.)

\begin{tabular}{|r|r|c|c|c|c|c|c|c|}
\hline 1835 & 96,66 & 76,35 & 73,80 & 69,67 & 76,04 & 84,43 & 52,41 & 81,41 \\
\hline 1836 & 94,92 & 86,07 & 81,70 & 84,15 & 75,17 & 93,23 & 65,08 & 80,84 \\
\hline 1837 & 102,68 & 83,93 & 86,18 & 81,84 & 85,24 & 98,50 & 70,10 & 92,56 \\
\hline 1838 & 101,02 & 87,01 & 87,90 & 96,50 & 79,04 & 98,50 & 60,65 & 85,90 \\
\hline 1839 & 116,30 & 60,91 & 70,84 & 89,19 & 48,02 & 94,11 & 57,31 & 52,56 \\
\hline 1840 & 132,35 & 51,68 & 68,40 & 83,19 & 41,79 & 99,38 & 78,39 & 46,11 \\
\hline 1841 & 122,28 & 60,06 & 73,44 & 85,02 & 52,56 & 98,25 & 70,09 & 55,25 \\
\hline 1842 & 120,38 & 71,43 & 85,98 & 82,48 & 77,09 & 98,50 & 106,98 & 80,97 \\
\hline 1843 & 127,90 & 61,29 & 78,39 & 84,26 & 60,02 & 99,39 & 89,57 & 62,97 \\
\hline 1844 & 136,72 & 55,82 & 76,33 & 83,56 & 58,73 & 99,39 & 73,81 & 61,26 \\
\hline 1845 & 133,76 & 54,97 & 73,52 & 85,56 & 52,24 & 97,99 & 70,18 & 55,72 \\
\hline 1846 & 130,85 & 61,15 & 80,02 & 84,96 & 66,22 & 97,99 & 74,02 & 70,54 \\
\hline 1847 & 133,39 & 67,39 & 89,89 & 84,66 & 93,23 & 97,99 & 72,13 & 99,24 \\
\hline 1848 & 157,90 & 49,70 & 78,47 & 83,85 & 64,77 & 93,23 & 79,43 & 67,82 \\
\hline 1849 & 138,32 & 54,52 & 75,41 & 80,68 & 61,47 & 96,75 & 65,70 & 63,81 \\
\hline 1850 & 125,28 & 58,86 & 73,75 & 81,79 & 55,85 & 93,81 & 79,26 & 57,06 \\
\hline 1851 & 124,17 & 60,85 & 75,55 & 78,71 & 59,47 & 92,35 & 100,21 & 60,92 \\
\hline 1852 & 124,91 & 58,76 & 73,39 & 80,14 & 54,27 & 91,47 & 97,45 & 56,15 \\
\hline 1853 & 124,89 & 65,81 & 82,19 & 80,75 & 72,50 & 91,47 & 112,74 & 73,39 \\
\hline 1854 & 102,54 & 82,30 & 84,39 & 80,99 & 80,77 & 91,47 & 96,55 & 81,64 \\
\hline
\end{tabular}


CUADRO A 1 (Cont.)

\begin{tabular}{|c|c|c|c|c|c|c|c|c|}
\hline & TFP & Precios agrarios & Costes de producción & Salario & Renta + diezmo & Alquiler de yunta & Fertilizantes & Semilla de trigo \\
\hline 1855 & 96,72 & 87,74 & 84,87 & 84,13 & 78,47 & 94,39 & 93,07 & 78,24 \\
\hline 1856 & 100,00 & 100,00 & 100,00 & 100,00 & 100,00 & 100,00 & 100,00 & 100,00 \\
\hline 1857 & 103,39 & 106,57 & 110,18 & 109,93 & 112,32 & 114,92 & 95,98 & 112,16 \\
\hline 1858 & 112,18 & 89,26 & 100,13 & 113,29 & 83,79 & 109,06 & 94,60 & 82,61 \\
\hline 1859 & 104,76 & 93,89 & 98,36 & 104,13 & 87,49 & 102,37 & 111,71 & 84,64 \\
\hline 1860 & 98,94 & 101,99 & 100,91 & 107,35 & 88,44 & 114,34 & 98,26 & 87,81 \\
\hline 1861 & 103,75 & 100,19 & 103,95 & 111,32 & 92,58 & 105,98 & 112,25 & 92,52 \\
\hline 1862 & 111,86 & 95,27 & 106,57 & 116,78 & 93,51 & 105,10 & 119,30 & 91,30 \\
\hline 1863 & 115,50 & 93,06 & 107,49 & 120,82 & 91,19 & 104,08 & 126,85 & 88,15 \\
\hline 1864 & 143,48 & 72,78 & 104,42 & 114,17 & 85,02 & 109,06 & 140,77 & 82,18 \\
\hline 1865 & 154,07 & 63,47 & 97,79 & 110,02 & 72,50 & 109,06 & 144,44 & 69,98 \\
\hline 1866 & 144,46 & 66,42 & 95,96 & 108,11 & 74,80 & 94,55 & 147,61 & 72,40 \\
\hline 1867 & 126,48 & 81,42 & 102,99 & 103,73 & 109,71 & 94,55 & 98,31 & 103,70 \\
\hline 1868 & 129,27 & 80,71 & 104,34 & 107,41 & 112,12 & 109,06 & 70,31 & 102,97 \\
\hline 1869 & 127,64 & 74,53 & 95,13 & 103,14 & 86,16 & 102,32 & 91,18 & 77,90 \\
\hline 1870 & 135,58 & 75,49 & 102,35 & 110,32 & 99,43 & 98,07 & 96,17 & 90,58 \\
\hline 1871 & 122,91 & 85,70 & 105,33 & 113,49 & 100,27 & 98,50 & 111,78 & 91,44 \\
\hline 1872 & 107,85 & 88,37 & 95,31 & 110,31 & 83,75 & 97,92 & 81,94 & 76,43 \\
\hline 1873 & 116,62 & 84,04 & 98,01 & 108,85 & 82,00 & 100,26 & 126,68 & 72,48 \\
\hline
\end{tabular}


CUADRO A 1 (Cont.)

\begin{tabular}{|r|r|r|r|r|r|r|r|r|}
\hline 1874 & 117,66 & 86,52 & 101,80 & 120,78 & 89,54 & 98,50 & 89,58 & 79,52 \\
\hline 1875 & 117,70 & 85,77 & 100,96 & 116,59 & 90,71 & 100,85 & 89,33 & 78,93 \\
\hline 1876 & 106,74 & 99,14 & 105,82 & 125,48 & 96,99 & 105,54 & 76,00 & 85,97 \\
\hline 1877 & 101,31 & 106,79 & 108,19 & 120,77 & 104,36 & 101,14 & 100,43 & 88,33 \\
\hline 1878 & 117,91 & 96,27 & 113,50 & 125,41 & 120,40 & 98,50 & 91,66 & 99,63 \\
\hline 1879 & 120,57 & 101,89 & 122,84 & 126,05 & 125,93 & 123,86 & 113,52 & 108,90 \\
\hline 1880 & 102,99 & 112,88 & 116,26 & 132,91 & 107,04 & 116,09 & 101,16 & 90,76 \\
\hline 1881 & 116,64 & 110,83 & 129,27 & 151,99 & 118,03 & 117,85 & 115,32 & 105,20 \\
\hline 1882 & 118,02 & 111,60 & 131,70 & 135,97 & 135,66 & 124,30 & 136,52 & 113,28 \\
\hline 1883 & 113,82 & 111,18 & 126,55 & 137,96 & 114,27 & 132,81 & 134,95 & 95,98 \\
\hline 1884 & 125,63 & 90,97 & 114,29 & 130,99 & 92,58 & 126,65 & 130,11 & 77,92 \\
\hline 1885 & 108,90 & 106,73 & 116,22 & 137,90 & 88,48 & 127,68 & 143,30 & 74,96 \\
\hline 1886 & 124,55 & 97,51 & 121,44 & 134,76 & 97,06 & 144,24 & 146,76 & 82,14 \\
\hline 1887 & 134,80 & 91,75 & 123,68 & 137,02 & 104,96 & 124,30 & 155,72 & 94,51 \\
\hline 1888 & 129,47 & 88,81 & 114,97 & 124,19 & 99,90 & 128,11 & 128,98 & 85,51 \\
\hline 1889 & 113,11 & 96,14 & 108,74 & 128,74 & 84,94 & 128,99 & 103,47 & 74,13 \\
\hline 1890 & 116,05 & 92,28 & 107,09 & 114,10 & 93,74 & 133,69 & 98,06 & 82,23 \\
\hline 1891 & 112,46 & 102,30 & 115,05 & 124,05 & 103,74 & 133,69 & 100,82 & 92,48 \\
\hline 1892 & 135,32 & 84,02 & 113,69 & 121,81 & 106,09 & 124,30 & 101,66 & 94,35 \\
\hline 1893 & 178,35 & 63,84 & 113,86 & 118,78 & 99,82 & 133,69 & 127,39 & 88,06 \\
\hline
\end{tabular}


CUADRO A 1 (Cont.)

\begin{tabular}{|c|c|c|c|c|c|c|c|c|}
\hline & TFP & Precios agrarios & Costes de producción & Salario & Renta + diezmo & Alquiler de yunta & Fertilizantes & Semilla de trigo \\
\hline 1894 & 190,30 & 55,47 & 105,57 & 117,99 & 84,21 & 133,69 & 106,53 & 73,70 \\
\hline 1895 & 180,89 & 60,29 & 109,06 & 121,96 & 89,50 & 133,69 & 107,29 & 76,81 \\
\hline 1896 & 164,24 & 70,08 & 115,11 & 122,08 & 108,09 & 140,72 & 88,59 & 92,60 \\
\hline 1897 & 119,84 & 97,26 & 116,55 & 123,16 & 120,75 & 133,69 & 71,95 & 103,14 \\
\hline 1898 & 118,85 & 101,73 & 120,91 & 124,32 & 127,67 & 133,69 & 88,39 & 104,25 \\
\hline 1899 & 135,65 & 83,41 & 113,14 & 118,29 & 110,28 & 133,69 & 91,57 & 89,17 \\
\hline 1900 & 125,07 & 90,45 & 113,13 & 113,65 & 116,43 & 133,69 & 92,55 & 91,54 \\
\hline
\end{tabular}

Fuentes: Las detalladas al final del texto. 